\title{
Formulating optimal business process change decisions using a computational hierarchical change management structure framework: A case study
}

\author{
Abdulrahman Alrabiah \\ School of Information and Communication Technology, \\ Griffith University Gold Coast Campus, Southport, Australia and \\ Saudi Arabian Monetary Authority, Riyadh, Saudi Arabia, and \\ Steve Drew \\ Tasmanian Institute of Learning and Teaching, Academic Division, \\ University of Tasmania, Hobart, Australia
}

\begin{abstract}
Purpose - This paper firstly examines how business process change decisions (BPCDs) were implemented in a government organisation bound by tightly-coupled temporal constraints (TTCs). Secondly, it focuses on how to achieve optimal and efficient BPCDs that require tight compliance with regulators' temporal constraints. Finally, it formulates a rigorous framework that can facilitate the execution of optimal BPCDs with maximum efficiency and minimal effort, time and cost.
\end{abstract}

Design/methodology/approach - Decision making biases by individuals or groups in organisations can impede optimal BPC implementation; to demonstrate this a case study is investigated and the formulated framework is applied to tackle these failings.

Research findings - The case study analysis shows $76 \%$ of the BPCDs implemented were inefficient, mostly due to poor decisions and these resulted in negative ripple effects. In response, the newly developed hierarchical change management structure (HCMS) framework was employed to empower organisations to execute high velocity BPCDs, enabling them to handle any temporal constraints imposed by regulators or other exogenous factors. The HCMS framework was found to be highly effective, scoring an average improvement of more than $100 \%$ when measured using decision quality dimensions. This paper would be of value for business executives and strategic decision-makers engaging with BPC.

Research limitations/implications - The HCMS framework has been applied in a single case study as a proof of concept. Future research could extend its application to broader domains that have multi-attribute structures and environments. The evaluation processes of the proposed framework are based on subjective metrics. Causal links from the framework to business process metrics will provide a more complete performance picture.

Practical implications - The outcome of this research assists in formulating a systematic BPCD framework that is otherwise unavailable. The practical use of the proposed framework would potentially impact on quality outcomes for organisations. The model is derived from decision trees and analytical hierarchical processes and is tailored to address this problematic area. The proposed HCMS framework would help organisations to execute efficient BPCDs with minimal time, effort and cost. The HCMS framework contributes to the academic literature on BPCD that leverages diverse stakeholders to engage in BPC initiatives.

Originality/value - The research presents a novel framework - the hierarchical change management structure - that provides a platform for organisations to easily determine and solve hierarchical decision structure problems, thereby allowing them to efficiently automate and institutionalise optimal BPCDs.

Keywords Business process change decisions (BPCDs), hierarchical change management structure (HCMS), tightly-coupled temporal constraints (TTCs).

Paper type Research paper

\section{Introduction}

This paper examines the uses of business process change (BPC) initiatives in the public sector that are imposed by government or regulators with tightly-coupled temporal constraints (TTC) (i.e. minimum time and cost). Bound by 
these temporal constraints, organisations have often failed to execute BPC due to incomplete foundations for the decision making structure (Gong \& Janssen, 2017; Harmon, 2014; Jurisch, 2014; Raghu \& Vinze, 2007). Business process change decisions (BPCDs) made under these conditions often result in mediocre quality, sub-optimal BPC implementation, and non-compliance with government requirements (Varun Grover \& Otim, 2009; Jurisch, 2014). Varun Grover and Otim (2009) argued that reaching optimum decisions involves a systematic and holistic quantification of all BPC factors. However, current BPC frameworks fail to achieve this. Ideally, BPCD involves the application of plausible decision models to optimise BPC implementation (Han, 2003; Sikdar \& Payyazhi, 2014).

Optimal BPC implementation is based on a well-structured formulation of decision making (Guha, Grover, Kettinger, \& Teng, 1997; Harmon, 2015; Jurisch, Rosenberg, \& Krcmar, 2016; Vanhoenacker, Bryant, \& Dedene, 1999). However, contemporary organisations are encountering BPC challenges in public sectors due to the complex intra and inter-organisational relationships that trigger ripple effects, chaotic business system behaviour (Gong \& Janssen, 2017; Kherbouche, Ahmad, Bouneffa, \& Basson, 2013; Luftman, Lewis, \& Oldach, 1993; Snowden \& Boone, 2007), decision making biases, and other anomalies (Varun Grover \& Otim, 2009; Harmon, 2010; Jurisch, 2014; Jurisch, Ikas, Wolf, \& Krcmar, 2013). In the business context, ripple effects are explained as the collision between outcomes of activities in one system or process, prompting impacts to one or more related processes or systems (Lee, 1998; Luftman et al., 1993; Yau, Collofello, \& MacGregor, 1978). There is, therefore, a demonstrated need to explore the causes of these problems, and create a foundation for a quality, high momentum decision making model to tackle these impediments. Therefore, this aspires the researchers to develop an efficient and automated BPCD framework that can analyse and solve these issues.

The research was designed to address imperfections in BPC decision making that are not adequately explored or not previously addressed in the literature (Varun Grover \& Otim, 2009; Jurisch, Cuno, Palka, Wolf, \& Krcmar, 2012). To explore this issue further, we selected the Hafiz Program in the Kingdom of Saudi Arabia (KSA) as a case study for implementing and testing the proposed framework. The Hafiz Program is an initiative for resolving growing unemployment problems by providing financial incentives for genuine job seekers (Al-Harbi, 2012; Aluwaisheg, 2012). The Ministry of Labour was asked to implement the BPCD intervention in less than three months. This set the project on an aggressive BPC path and imposed on the ministry a set of very complex constraints to solve unemployment problems within a short period of time which we refer to in this paper as tightly-coupled temporal constraints (TTCs). In addition, the Hafiz Program had complex relationships and enormous stakeholders' diversity such as government and private agencies that connected to validate the eligibility of job seekers, presenting the ministry with colossal challenges in achieving its objectives.

These challenges can be summarised as a lack of time and resources, conflicting information, and complex relationships (Varun Grover \& Otim, 2009; Harmon, 2010; Jurisch, 2014; Jurisch et al., 2013). Furthermore, ad hoc decisions were made by executives and senior management based on partial information, providing narrow alternatives and promoting a focus on nonstrategic values, all of which exacerbated the challenges. Consequently, to achieve the ultimate objectives of BPCD implementation, the organisation (Hafiz) was forced to operate in a 'firefighting' mode - handling emergencies as they arose rather than approaching the process in a rational manner with attention to medium- and long-term planning.

To assist in the resolution of these challenges, a new computational HCMS framework is proposed by this study to formulate and institutionalise BPCDs. The HCMS is derived from extant literature that has described decision trees, hierarchical decision processes, and system dynamics as BPC tools (McNamee \& Celona, 2005; Paul, Yeates, \& Cadle, 2014; Rosenberg, Jurisch, Schermann, \& Krcmar, 2014; Sterman, 2000). The paper used the novel workshop-based model, named the HCMS Elicitation Workshop (HEW) by (Alrabiah \& Drew, 2018), to facilitate and enable the construction of the proposed HCMS framework by systematically eliciting the information from diverse stakeholders (Cardoso, Almeida, Guizzardi, \& Guizzardi, 2013). The principal rationale for this framework was to enable an organisation to model its BPCD precisely and plausibly (Houy, Fettke, \& Loos, 2015). It also supports the use of 
computer systems to optimise decision quality and minimise the time required for the execution of rigorous decision processes (Ploesser, Recker, \& Rosemann, 2008), thereby complying with any TTC.

The objectives of this research were the acquisition of an in-depth understanding of the issues that impede optimal BPCDs and to focus on critical points such as the impacts of complex decisions on BPC. A further objective was to contribute to the BPC theory by proposing a systematic solution for BPC decision management problems that are specifically generated from improper decisions. Therefore, the research paper seeks to identify the optimal and efficient BPC implementation alternatives by applying decision science.

The proposed HCMS framework solves some critical issues in BPCD that have not been satisfactorily addressed, such as the effects of a complex hierarchical structure, mixed relationships, ripple effects, chaotic behaviours and decisionmaking biases. As a result, due to the organisation's complex causal relationships, the negative ripple effect especially where there are TTCs in BPC - poses a great challenge because it introduces new problems, devalues the efficiency of BPC implementation, and may induce a chaotic effect (Rosenberg et al., 2014). Thus, this research paper seeks to introduce a systematic foundation for an optimal and efficient BPCD framework that enables an organisation to quickly and efficiently make BPCDs from holistic perspectives. Many decision-makers have different preferences, values or interests which influence different business processes. In some cases, issues are intentionally hidden, which has a significant effect on BPCD. Specifically, behaviours associated with biases and anomalies exist in organisations and affect the efficiency of BPCD. In order to restructure and reprioritise effectively, organisations require a usable decision making model that can systematically rate and evaluate alternatives (Alotaibi \& Liu, 2017). One such model is the decision trees (McNamee \& Celona, 2005). This model uses statistical probability to define the best alternatives for undertaking an action. Other models include the analytical hierarchy process model, which uses criteria and subcriteria structure techniques to identify alternatives (Gwo-Hshiung, Tzeng, \& Huang, 2011), and the Bayesian Networks probability model, which determines a sequence of variables through nodal connections (Seligman, Lehner, Smith, Elsaesser, \& Mattox, 2000). It was decided that the decision trees would be the most effective in automating the design of BPCDs (Paul et al., 2014). Decision trees offer a visualisation technique that assists to develop a BPCD framework that will compute, measure, govern, classify, explain and evaluate (Goodwin \& Wright, 2014; Grunig \& Kuhn, 2013; Quinlan, 1986). These advantages give decision trees the edge over other approaches.

This research paper considers a potential improvement to BPCDs implemented under tightly-coupled temporal constraints. We are only considering one case in this paper to demonstrate its application and efficacy, as a technique to improve BPC implementation. Thus, the following question is posed:

RQ1. How can optimal BPC decisions in government organisations that are bound by tightly-coupled temporal constraints be made more efficiently?

\section{Review of Literature}

2.1. Business Process Change in the Public Sector

Since the beginning of the Industrial Revolution, the industrial structure of the world has been in a continuous process of change (Abernathy \& Townsend, 1975; Davenport \& Short, 1990). With the passage of time, many modern technologies have been introduced to improve different modes of production and to increase customer satisfaction (Davenport, 2013; V. Grover \& Kettinger, 2000; Hammer, 1990; Neumann, 2014; Sterman, 2000). One of the strategies to enhance customer satisfaction is known variably as BPC (Grover \& Kettinger, 1998) or business process innovation (Abernathy \& Townsend, 1975; Davenport, 2013) that aims to formulate and re-structure decision making processes (Varun Grover, 1999). This strategy is used to evaluate all the ongoing internal and external activities of an organisation, and suggests replacement of the existing modes of production with those that are more effective or more efficient to keep the organisation performing optimally (Grover \& Kettinger, 1998; Harmon, 2003; Jurisch, 2014; Jurisch et al., 2012; Neumann, 2014). Changes brought about by this strategy are most often radical in nature rather than incremental (Davenport \& Stoddard, 1994; Varun Grover, 1999; Hammer \& Champy, 2009). This procedure could also be defined as a strategy-driven organisational initiative to improve the system's state or redesign the 
structure of business processes (Adesola \& Baines, 2005; Jurisch, Palka, Wolf, \& Krcmar, 2014). Such changes provide competitive advantages through changes in information, technology, management, organisational structure and workforce optimisation (Guha et al., 1997; Harmon, 2003; Rosenberg et al., 2014).

\subsection{Business Process Change Challenges}

Studies show that several public sector organisations can be categorised as change-opposed, due to enforced restrictions on the use of technology as it is used in competitive commercial firms (Jurisch, 2014; Stemberger \& Jaklic, 2007). For this reason, BPC is often not implemented in the public sector as effectively as it is applied in the private sector (Lau, 2003; Neumann, 2014). In addition, the government sector has regulatory features with a compartmentalisation of confidential information that requires an elevated level of security and privacy. Such decentralised control promotes multiple levels of decision making, and in many cases the political or department leaders show a significant level of reluctance regarding the adoption of BPC strategies (Bum \& Robins, 2007).

To effectively implement a change-responsive system, the government sector first requires the acquisition of technical and general skills to set up an e-government environment (Al-Mashari \& Zairi, 1999; Durcikova \& Gray, 2009). There are instances where BPC has been implemented in the government sector (Jaklič \& Štemberger, 2005; Scholl, 2004; Stemberger \& Jaklic, 2007). However, this initiative is still not supported by an automated technology which moderates the effectiveness and efficiency of this strategy. A fundamental challenge when implementing this strategy relates to some government sectors' conservative attitudes toward change (AlShihi, 2006; Neumann, 2014). An organisation needs a top-down mode with an 'enterprise-wide leadership' approach that includes 'end-to-end process optimization', rigorous governance and an enforcement policy to achieve optimal change and meet stakeholder's expectations (Alotaibi \& Liu, 2017; Burlton, 2015; Fisher, 2004). (Lönn \& Uppström, 2013) also argued against disregard for bottom-up instruction practice in order to achieve success in business process implementation. Secondly, the scope of the suggested change is often considered and then moderated to reflect the extent of the current problem. Under such moderating circumstances, there is a tendency to adopt only those IT applications and approaches that are likely to be helpful but do little to change the system (Fountain, 2001). This is due to the knowledge gap and uncertainty the business staff have about IT, which diminishes the capability of the technology (Andrade, van der Aa, Leopold, Alter, \& Reijers, 2016; Fisher, 2004). The issues that impede organisations from achieving optimal managerial change processes are due to factors such as limited technical knowledge, uncertainty, disintegration, inappropriate communication, decision making biases either by individuals or groups, and resistance (Ariouat, Hanachi, Andonoff, \& Benaben, 2017; McKenzie, van Winkelen, \& Grewal, 2011; Sikdar \& Payyazhi, 2014). Thus, proposing an executable, hierarchical change management framework may be beneficial for optimal BPC (Brenner, Coners, \& Matthies, 2015; Burlton, 2015; Cadle, Paul, \& Turner, 2010; Paul et al., 2014).

The study by Javidroozi et al. (2014) concluded that reducing human factors would significantly improve the BPC. In addition, they pointed out that the enormous cost and time required to implement BPC needed to be addressed, which are the two factors in the HCMS computational framework. The frequent change of leadership in the government sector and lack of change completion keeps BPC from having an impact on this sector, as the goals of the organisation become inconsistent and ill-defined (Wang, Medaglia, \& Zheng, 2017). Under such circumstances, identifying the functional and non-functional goals of an organisation can be a laborious mission (Cardoso et al., 2013; Varun Grover \& Otim, 2009; Luo \& Alex Tung, 1999; Wu, 2002). Fountain (2001) argued that the administrative structure has mainly evolved to manage financial, legal and many other such issues that ultimately reinforce the already existing bureaucratic approach of the system. However, the structure of most government sectors is based on rules and regulations that strongly resist any changes in the administrative structure (Law, Lau, Kerrigan, \& Ekstrom, 2014; Zuiderwijk \& Janssen, 2014). Law et al. (2014) argued for an innovative technology 'computational model' to mitigate challenges and improve government regulation output. 


\subsection{Business Decision Making}

In the context of this study, in government workplaces the worker is often not directed to a suitable decision making model by the prevailing business process models and management approaches (Afflerbach, Bolsinger, \& Röglinger, 2016; Smart, Maddern, \& Maull, 2009). Such a decision making model, however, is essential to achieve optimal BPC (Harmon, 2014; Pateli \& Philippidou, 2011). Numerous external factors bring a change to business processes (e.g. new technologies, compliance with industry standards and government rules, changes in the business field, shareholders' needs, or economic factors pertaining to globalisation) (Fan \& Zhao, 2017), but often the decision making process is neither well-structured or automated (Al-Mashari \& Zairi, 1999; M. Amiyo, Nabukenya, \& Sol, 2010; Bandara, Gable, \& Rosemann, 2005; Cameron \& Green, 2015; Goedertier \& Vanthienen, 2006; Trkman, 2010). A change in the business environment can thus lead to a change in business strategies of variable extent and may be implemented by launching small-scale automation until the entire process can be computerised to achieve optimal BPCDs (Cameron \& Green, 2015; Soffer, 2005; Thomas, 2008). In the public sector, the changes are mainly imposed by exogenous organisations, such as a government's cabinet, regulatory bodies, and industrial standards agencies (Jurisch et al., 2013). Most organisations don't implement a rigorous and consistent BPCDs (Javidroozi, Shah, Amini, \& Feldman, 2016; Jurisch et al., 2012). This leads to ambiguity and causes uncertainty in acting promptly on BPC implementation (Jurisch, 2014).

The presently available process management models do not guide the manager toward an effective process configuration (Harmon, 2010; Smart et al., 2009; Weske, 2012; Zairi, 1997). Issues such as decision making limitations, biased decisions, the effect of decisions on processes, the link between process goals and change decisions, the situations in which the decision is likely to be effective, and the limitations of decisions, are not dealt with efficiently (Alotaibi \& Liu, 2017; Kavakli \& Loucopoulos, 1999; Rinderle, Reichert, \& Dadam, 2004; Wang et al., 2017). Further, when there is a change in an organisation, irrespective of the level of change, the low capability of the organisation to react swiftly and, hence, deal with the change problem is a basic challenge for its competitiveness (Goedertier \& Vanthienen, 2006; Jurisch et al., 2014). Thus, the decision making process is integral to an organisation's efficiency and directs the gauging of individual choices, leading to trade-off analysis (Subramanian \& Ramanathan, 2012). In the context of this study, the literature suggested that rigorous decision models in BPC are not well addressed. In addition, uncomplicated and straightforward decision making in organisations is very important to reach optimum BPC and ultimately to improve services (M. R. Amiyo, 2012; Wang et al., 2017).

\subsection{Towards Informed Change Management Decisions}

Many decision makers at the time of making change management decisions are unable to gauge all parts of a problem or opportunity (Kolbin, 2003; Saaty, 1990a; Simon, 1979). They are unclear about the possibilities and threats, confused about possible implications, and what is vital or inconsequential to the decision (Snowden \& Boone, 2007). Similarly, required data may be incomplete, possible options are not considered, and repercussions have not been wholly identified (McNamee \& Celona, 2005; Snowden \& Boone, 2007). Such behaviours correlate with the complexity of the decision structures and hierarchically complex relationships, possibly combined with the unavailability of decision information, decision biases and the ambiguity of alternatives (Grunig \& Kuhn, 2013; Law et al., 2014; McKenzie et al., 2011; Paul et al., 2014; Simon, 1979; Wang et al., 2017). Such circumstances induce decision delays and generate a ripple effect with the process change (Herzog, Usatin, \& Fizazi-Hawkins, 2014; Kherbouche et al., 2013). Thus, significant collaboration and discussion among stakeholders is required to understand the full range of decision-influencing factors (Al-Mashari \& Zairi, 1999; McKenzie et al., 2011).

Decision analysis generates knowledge of the factors that are essential to the decision process (Paul et al., 2014; Rao, Mansingh, \& Osei-Bryson, 2012). It also ascertains their relative value or weighting among possible choices (McNamee \& Celona, 2005). It would, therefore, be advantageous to design a rigorous, quantifiable change management decision making model that can measure organisational values to evaluate impacts (Gong \& Janssen, 2012; Huizing, Koster, \& Bouman, 1997; Škrinjar \& Trkman, 2013), and quickly select the right alternatives quantitatively (Cadle et al., 2010; Langer, 2017; Paul et al., 2014). 


\subsection{Analytical Hierarchy Process in Decision Making}

Introduced by Saaty (1977), the Analytical Hierarchy Process (AHP) is an effective methodology in decision process measurements (Andin Wu \& L' abbe Wu, 1991; Triantaphyllou \& Mann, 1995). With regards to certain criteria and overall goals, the main objective of the AHP is to make the best choice among the available alternatives (Andin Wu \& L' abbe Wu, 1991; Rao et al., 2012). Triantaphyllou and Mann (1995) indicated that the AHP has served as the point of departure from which other decision-making methods were created. Despite its growing acceptance, it has attracted considerable criticism on both the theoretical and the practical fronts (Triantaphyllou \& Mann, 1995). One of the drawbacks of AHP is the absence of factual measurements (i.e. it depends heavily on the subjective evaluations of the decision makers). See (Saaty, 1977, 1990b, 2008) for a review. Furthermore, the broad analysis of AHP by Subramanian and Ramanathan (2012) showed that AHP applications were limited and needed more investigation and experiments to tackle decision process gaps, such as decision prioritisation methodology, decision trade-off analysis, and decision feedback analysis. To deal with the complexity of the hierarchical decision issues, an executable decision analysis model (HCMS) was developed by creating a hybrid of Decision Trees and the AHP features (McNamee \& Celona, 2005; Paul et al., 2014; Saaty, 1990b, 2008).

In this paper, the developed HCMS framework addresses the shortcomings in BPCD by calculators (cost, time, priority selection and feedback analysis) to achieve the best business process decision among the available alternatives. In addition, the proposed HCMS framework provides decision makers with a holistic overview of all the related business processes and applications from which to execute the desired objectives (see Figure 1).

\section{Hierarchical Change Management Structure (HCMS) Framework}

Required information was elicited for the development of the HCMS framework based on the workshop technique used in a case study of the Hafiz Program in KSA (see section 4.1 below). This framework was adopted and tailored from the Quality Attribute Workshops (QAWs) of the Software Engineering Institute (SEI), (Barbacci, 2003). The QAWs is designed to accomplish the Architecture Trade-off Analysis Method to define an organisation's needs and determine substantial quality attributes to understand the system's architecture structure and define stakeholder relationships. The HCMS framework was constructed by eliciting decision information from each organisational level from the top-down, using a newly developed methodology by the researchers called HCMS Elicitation Workshop (HEW) (Alrabiah \& Drew, 2018).

Figure 2 summarises the phases and the sequential process steps used to elicit the processes to determine the HCMS. Basically, the HEW technique enables the organisations to elicit the required information to create a hierarchical change management structure by using the quality attribute workshop technique (Barbacci, 2003). This process, called the Organizational BPC Factors Elicitation Workshop, consists of 15 steps that are drawn from a focus group workshop. In the first phase, the organisation presents and elicits the organisational objectives and strategies, the organisational structure and governance, the business process architecture, and the application architecture. The next phase identifies the organisation's change management drivers and scenarios and includes brainstorming and generating scenario alternatives. The third phase consolidates and prioritises the elicited scenarios. The next phase generates an initial HCMS that identifies the causal relationships between the business processes from the selected, alternative scenarios. The next phase constructs the causal analysis models of the business processes based on the quantification of the time and cost (see equation $\mathrm{A}, \mathrm{B} \& \mathrm{C}$ below). In the subsequent phase the constructed initial HCMS is computed and evaluated. The computation process starts from the bottom to the top to identify the best alternative path to execute the objective (Lönn \& Uppström, 2013), based on the fastest time and cheapest path, as in the example in Figure 1. After the computation comes the verification phase which checks for any errors or anomalies before moving to the last step of documenting the HCMS. 


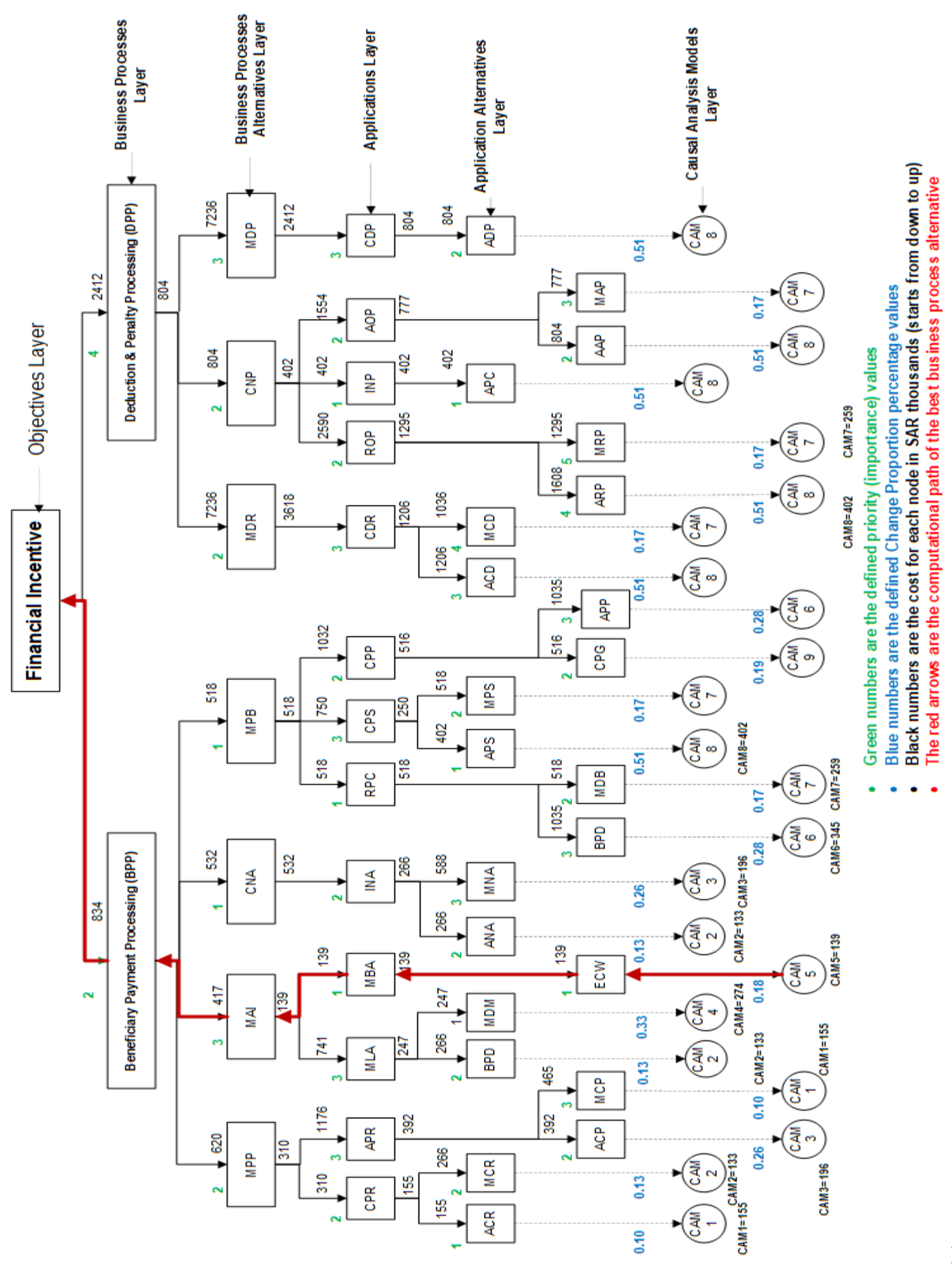

Figure 1. HCMS

computation example

*See the HCMS calculation sheet in Appendix 1 


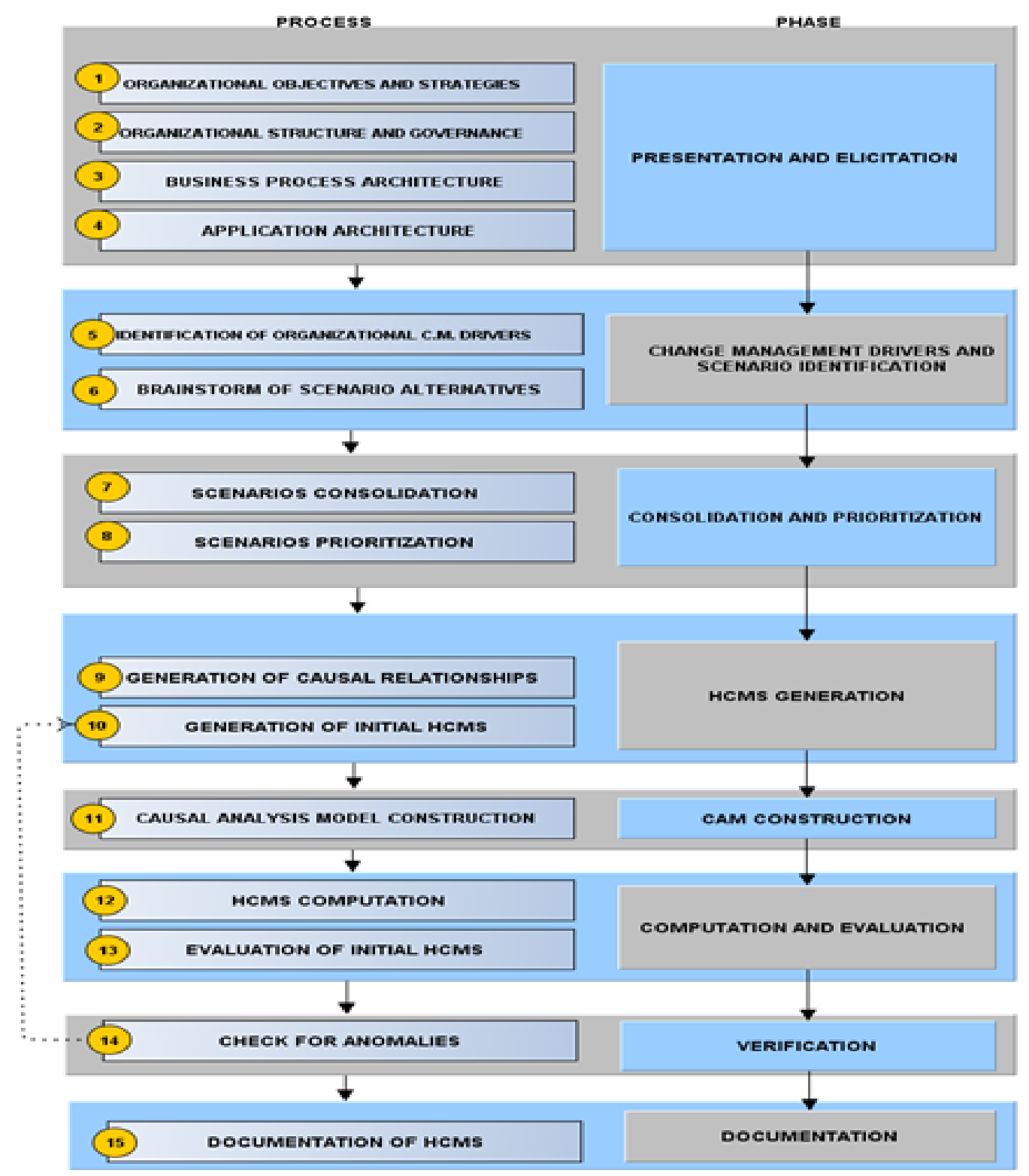

Figure 2 HCMS elicitation workshop (HEW) (Alrabiah \& Drew, 2018)

In this paper, the proposed HCMS framework allows the organisation to select the best alternatives that are most efficient and appropriate to execute the required BPCs. This structure increases an organisation's ability to make optimal BPCDs in different ways. Firstly, it minimises the associated cost that usually results from changes by minimising the required resources, reducing the estimated time to change, and diminishing the scope of impact. Secondly, it minimises the risks that an organisation might have by predicting possible threats introduced by the change process. It maximises the quality of the service and ensures there is no discrepancy once the appropriate change alternative is selected. Thirdly, HCMS can maximise the accommodation of change drivers to create driver-compliant change decisions. Additionally, the proposed structure enables the organisation to be compliant with change constraints, such as a limited temporal timeframe, and limited experience and resources (Gong \& Janssen, 2017).

The HCMS framework extends the extant literature in three ways. Firstly, the framework provides a systemic view of all the parameters involved in the execution of the business processes, including the objectives and the alternative business process. Secondly, it identifies the best alternative business process with regards to the two constraints of 
time and cost. Thirdly, the arrival at this best alternative is based upon a scientific calculation method that previous literature has lacked (see the HCMS computation example in Figure 1).

As part of the HCMS, the Causal Analysis Model (CAM) was constructed using a system dynamics causal loop diagrams (CLDs) technique (Rosenberg et al., 2014) to determine causal relationships (CR) between business processes for a given decision alternative.

$$
\begin{aligned}
& B P_{x . \text { Cost }}=\sum_{i=1}^{n} B P_{x . C P} * B P_{i . C R} * B P_{i . c o s t} \\
& B P_{x . \text { Time }}=\sum_{i=1}^{n} B P_{x . C P} * B P_{i . C R} * B P_{i . t i m e} \\
& B P_{i . C R}=\prod_{k=1}^{m} C R_{k}
\end{aligned}
$$

$\mathrm{CP}=$ Change proportion; $\mathrm{CR}=$ Causal relation .

$B P_{i . C R}$ calculates the product of all the CRs of the links of the path that connects $\mathrm{BP}_{\mathrm{i}}$ with the $\mathrm{BP}_{\mathrm{x}}$.

The total time and cost required for the implementation of a given business process is calculated by using equation (A) to compute the total cost of implementing a change for a given alternative BPC scenario. Equation (B) is used to compute the total time of implementing a change for a given alternative BPC scenario. Equation (C) is used to calculate the product of all the CRs of the path that connects the business processes. This assessment allows organisations to accurately determine the cost and time required for an alternative business process scenario before its execution (Gong \& Janssen, 2012). Therefore, this method allows organisations to efficiently select optimal business process alternatives and make the most advantageous change management decisions, thus reducing ripple effects.

\subsection{The Hafiz Program Case Study}

The Hafiz Program is a major welfare plan in the Kingdom of Saudi Arabia (KSA) that was selected as a case study for this research. In Arabic, the word 'hafiz' means 'incentive', and the program provides a living allowance and training for citizens who are jobseekers until they are employed. The program is accessed via a fully automated portal and services a huge pool of applicants of more than two million at any time. The program was launched in 2012 by the government to alleviate the problem of high unemployment rates in the shortest possible time. It was given only three months to be implemented. This task involved tremendous process changes and transformations in business focus.

The case study reported here was conducted after the Hafiz Program was implemented. Data collected throughout the phases of this case study was comprehensive, and the analysis indicated inappropriate BPCs that were caused by project constraints, such as limited time and resources. Subsequent analysis also revealed significant, improper changes in processes that occurred during the first 12 months of the project. In each instance, these resulted from inadequate information leading to poor decisions, disagreement, ambiguity in decision trees, and inappropriate decision making (Paul et al., 2014).

The implementation of BPC initiatives often faces challenges that hinder an organisation's achievement of successful change. The temporal frame for change and constraints imposed by government regulators to solve the unemployment rate caused Hafiz management to modify its goals and strategies. Unfortunately, such change was required using only the Ministry of Labour's existing knowledge, experiences, and the resources, which created considerable challenges. Dealing with such a vast number of users and consequent focus on delivering services to those users resulted in some change processes unintentionally being ignored. The subsequent ripple effects through sub-elements of the Hafiz Program were significant.

A contributing impediment to effective change was the lack of similar cases that could provide experiences and templates to which Hafiz management could refer. The adoption of modern technologies and policies to manage and 
control this system and the costs of gaining experience and related consequences were colossal. Other organisational barriers within Hafiz management included the absence of an unobstructed vision and strategies, knowledge gaps at the executive level, and complex hierarchical relationships. These barriers resulted in an inadequate information flow to decision makers and a perceived absence of feasible alternatives. Moreover, ripple effects, chaotic behaviours, decision making biases and other anomalies resulting from incorrect decisions gave rise to the need to make constant reactive changes in order to compensate.

\section{Research Methodology}

The research used mixed methods to explore and understand the research problems (Creswell, 2013). Three types of data were collected and analysed, involving operational data, a survey for each stakeholder group, and two phases of interviews: a first interview, and a follow-up interview. An analysis was also undertaken of the feedback systems using the system dynamics patterns technique.

The validation process was conducted using three techniques. Firstly, a decision quality chain technique was used to verify the output from the first interview and to measure the level of six constituents of decision quality (Matheson, 2005; McNamee \& Celona, 2005). Secondly, the system dynamics patterns technique (Sterman, 2000) was applied to validate the output of the analysed data (see pattern samples in Figure 3). Thirdly, the data from the follow-up interviews was analysed and compared to the analysis of the first interviews and with the data generated using the proposed framework through the stakeholder focus groups (Krueger \& Casey, 2014; Luna-Reyes \& Andersen, 2003; Rosenberg et al., 2014; Stufflebeam, 2001).

\subsection{Data analysis instruments}

System dynamics provides a powerful tool that can help to verify the analysed data (Forrester, 1997; Segatto, Inês Dallavalle de Pádua, \& Pinheiro Martinelli, 2013; Sterman, 2000). This methodology has been applied in the extant literature within diverse contexts (Azar, 2012), [e.g. strategic management (Hoque, Barnabè, \& Busco, 2012) and information sharing (Lin \& Shayo, 2012)]. This tool involves identifying the behaviour patterns of the defined variables, and it is possible to identify the causes of an event, compare behaviours, and fix the issues that emerge from the feedback loops in the business process structure (Barlas, 2007; Melão \& Pidd, 2000; Sterman, 2000). From the

patterns identified in Figure 3 by using the HCMS framework developed by the present study, it was possible to recognise the complexity and behaviours in the Hafiz Program systems and determine the causal relationships that affect the interactions between different processes (Rosenberg et al., 2014).

The first collected data was the operational data. It was targeted to narrow the scope of the analysis, and to help to design the surveys and focus on the main challenges. That data was gathered from Hafiz's Help Desk and Customer Relationship Management System. The operational data was classified under the headings Beneficiary Employment Rate, Unemployment Due to Hafiz, Beneficiary Violation Rate, Complaints, Technical Issues, Business Change Requests, Extra BPC efforts rate, Application Processing Time, Data Quality Anomalies, and Hafiz Applicants Rate. Figure 3 summarises some of the identified patterns that were based on the calculation of the mean of the aggregated data, the standard deviation, the mode of the data, and the skewness of the shape. In addition, it classified the analysed variables in terms of oscillation, over collapse, stasis, exponential (positive or negative) and improvement patterns. The last column illustrates the findings and explains the behaviour of the observed trends.

In the second phase, three surveys were developed, one for each of the stakeholder groups, nominated as beneficiary, business and technical. Each question in the survey has four periods (quarters) to identify and measure the changes and detect failures or success by using the Likert response scale from 1 (High) to 5 (Low). The purpose of the beneficiary questionnaire was to determine the perceived objectives of the Hafiz Program from the beneficiary's perspectives and provide a measure of the achievements of the program from their viewpoint. In addition, responses to the beneficiary survey can reflect the change management drivers and the positive or negative signs of improvement. 
Another objective of this survey was to provide a triangulation point to verify the collected data from both the business and technical stakeholder groups.

The Hafiz Program business employees' questionnaire aimed to identify the procedures of the BPC and examine how the Hafiz management implemented the changes. The questionnaire items included data about the interacting structure, addition of new requirements, BPC frequency, data quality, and complaint resolution. This questionnaire facilitated the analysis methodology by identifying most of the causes for the change failures. The third survey was for Hafiz Program technical staff and was designed to capture the technical issues that may impede the implementation of BPC, including system operation and user support.

In the beneficiary survey, the population was large (there are more than two million applicants in the Hafiz Program), therefore a stratified random sampling population was used, and 200 participants were selected as a sampling quantity. For that reason, the population was divided into three groups based on gender, age and education level to ensure that the result was not biased and not overlapping with other groups. In the technical and business survey groups, all the population was used because the number was small (i.e. 15 and 17 respectively).

Semi-structured interviews were conducted and aimed to justify the collected answers from the questionnaires and to elicit more information regarding the reasons for the occurrences, issues and common problems during the implementation of the program. In addition, the analysis verified the causes by applying the decision quality chain technique. Thus, 14 questions were elicited from the analysed data of the operational data and surveys phases. These questions were used to interview Hafiz's change management team, mainly focusing on the objectives, strategies, impediments, achievements, techniques and decisions processes. Then eight follow-up interview questions were designed, based on the answers of the first interviews phase and targeted to confirm the BPC challenges and determine if there were any impact measures, evaluations, alternative solutions and approaches of BPCDs to overcome these challenges. The questions sought to ascertain the causes of BPC failures, such as how the Hafiz Program dealt with uncertainty during the BPC and if there were any evaluation or alternative options to optimise the BPCDs.

4.2. Operational and Surveys Data Analysis Results

An analysis of the operational data indicated significant issues, including instability in the application processing time, beneficiary unemployment and violation rates, anomalies in data quality, growth in technical issues, increases in extra business process efforts and beneficiary complaints. The outputs of the variables indicated direct effects on process performance and efficiency and diminished improvement, which caused delays in process execution and complex interrelationships within the organisation.

From the surveys of the beneficiary, business and technical staff stakeholder groups' perspectives, continuous impediments and instabilities were found for most of the dimension variables. The surveys did indicate, however, that there was system improvement in portal availability, data quality and security. The rest of the measured variables showed declines in job-seeking reporting activity, service quality satisfaction, dispute resolutions and instabilities that reflected the existence of a ripple effect between business process interrelationships.

These findings were verified through focus group workshops with the stakeholders. The analysis indicated a much higher number of anomaly patterns compared to those indicating improvement. The overall survey results showed that $76 \%$ of potential BPCDs implementations encountered anomalies, accounting for 26 of the 34 verified patterns (there were four patterns not verified by the CM team). Only $23 \%$ or 8 out of 38 patterns showed potential for improvement (see Figure 4). The anomalies were generated from the ripple effects produced by unsound BPCDs. This result indicates that the firm failed to achieve the ultimate objectives of the BPC initiatives that were bound by tightlycoupled temporal constraints. 
DQ Anomalies from

(Op. Data) OCOL Pattern

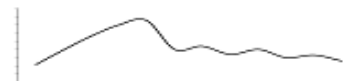

It seems that values in the beginning de monstrated improvement but later declined. This equated to no

improvement. From a system dynamics point of view it seems that a neqative feedback loop caused the decline after substantial improvement

Business Process Management from (Busines s Data) IMP Pattern

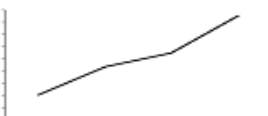

It is evident that there is improve ment in Business Process Management

Outsourced Company Technical Issues Rating from (Technical Data) EXP Pattern

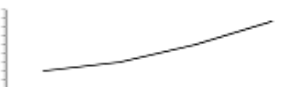

There is exponential growth of outsourced company technical issues This indicates that the problem is becoming more aggravated. There is a self-reinforced feedback loop that might be causing this pattern according to system dynamics analysis. This feedback might have been caused by a causal relationship between different

factors and organisations

Dispute Resolution Performance from (Busines s Data) OSC Pattern

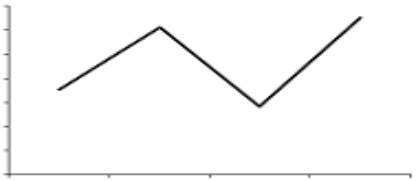

Unstable improvement and the values oscillate with time - no improvement. It seems that temporal feed back loop with a delay is causing th is problem because of a causal interrelationship of different factors and organisations
Efficiency of the HAFIZ's Information System from (Technical Data) IMP Pattern

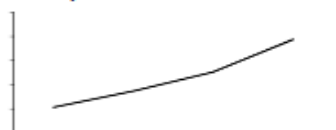

It is evident that there is improvement in efficiency of the HAFIZ Program's Information System

Efficiency of Es calating Issues from (Beneficiary Data) OSC Pattern

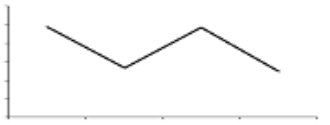

Unstable improvement and the values oscillate with time - no improvement. It seems that te mporal fe edback loop with a delay is causing this problem because of the causal interrelationship of different factors and organisations

Extra BPC Effort Rate from (Op. Data) EXP+Pattern

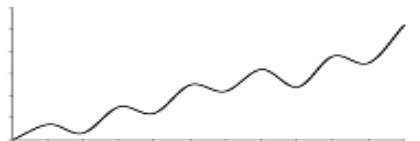

Exponential growth of the BPC Effort Rate indicates that the problem is becoming more aggravated. There is a self-reinforced feedback loop that might be causing this pattern according to system dynamics analysis. This feedback might have been caused by a causal relationship between different factors and organisations

Technical Issues from (Op. Data) EXP+Pattern

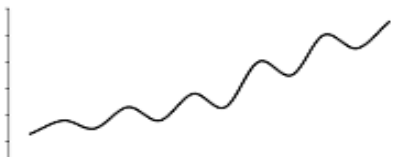

The exponential growth of technical issues indicated that the problem became more aggravated. There was a self-reinforced feedback loop that could have caused this pattern according to system dynamics analysis. This feed back might have been caused by a causal relationship between different factors and organisations
Benefic iary Violation Rate from (Op. Data) OSC Pattern

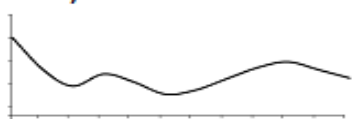

Unstable improvement and the values oscillated with time - no improvement. It seemed that temporal feedback loop with a delay caused this problem because of the inter-relation ship of different factors and organisations

Dis pute Resolution Satisfaction from (Beneficiary Data) OCOL Pattern

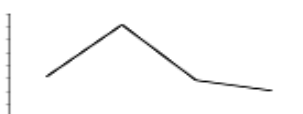

It seems that values improved in the beginn in but later declined. From a system dynamics point of view it seems that a negative fe edback loop is causing the decline after substantial improvement

Rate of Changes from (Business Data) EXP + Pattern

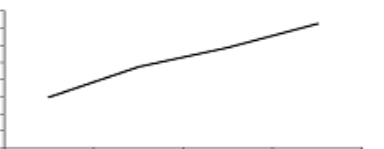

There is exponential increase in rate of change, which indicates the problem is becoming more aqqravated. The re is a self-reinforced feedback loop that might be causing this pattern according to system dynamics analysis. This feed back might have been caused by a causal relationship between different factors and organisations

Effectivenes s of Change

Management from (Business Data) OSC Pattern

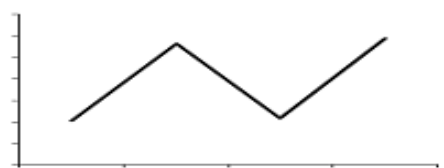

Unstable improvement and the values oscillate with time - no improvement. It seems that a temporal feedback loop with a delay is causing this problem because of a causal interrelationship of different factors and organisations

Figure 3: Selected Patterns Analysis from the Operational Data and Surveys

Note. $\mathrm{DQ}$ Anomalies $=$ data quality anomalies; Op data $=$ operational data; $E X P+=$ Exponential growth; $E X P-=$ Exponential Decline; STAS = Stasis; OSC= Oscillation; $\mathrm{OCOL}=$ Overshooting and Collapse; IMP=Improvement 


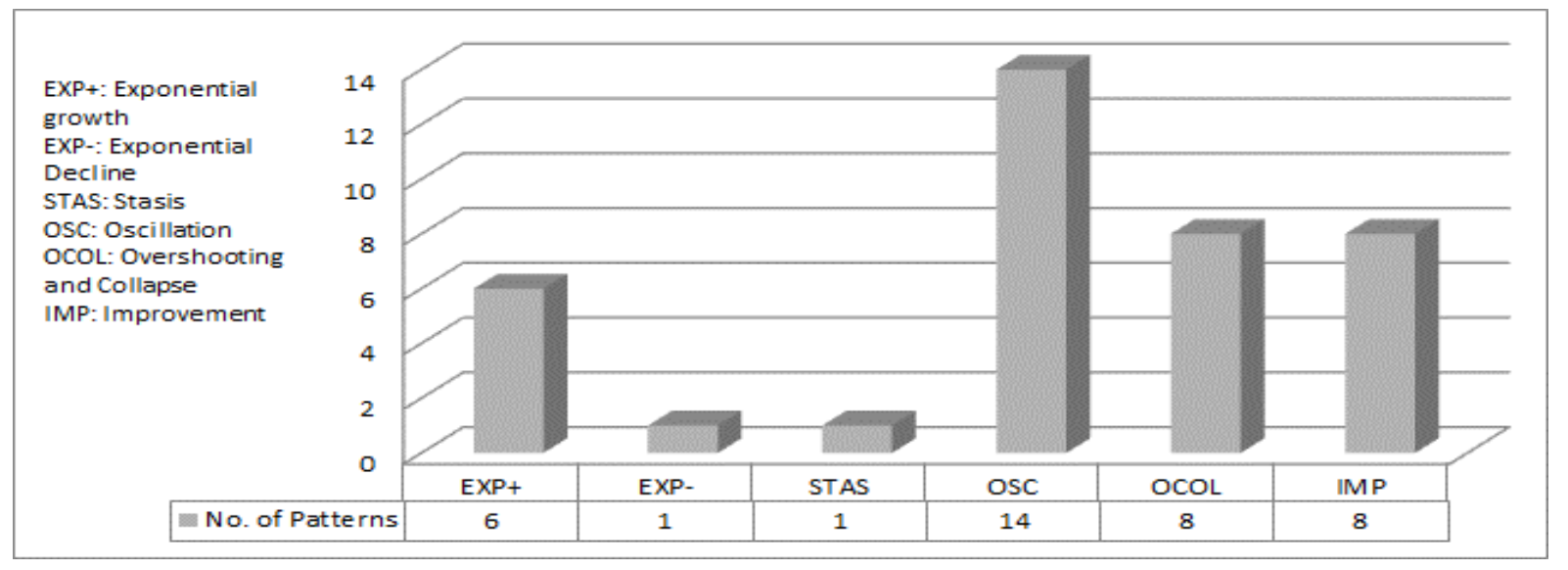

Figure 3 Surveys' overall patterns

\subsection{Interviews Analysis Results}

The six-constituent decision quality chain (Matheson, 2005) was used to measure and define the factors determined from the analysis of the interviews as being mainly responsible for the inefficiency of the BPCDs in the Hafiz Program (McNamee \& Celona, 2005). The results (see Figure 5) showed under-average values (2.5) in four factors, even though the Hafiz Program showed a high score for commitment to action. Therefore, a decision analysis method was adopted to solve the issues. The output showed six barriers that hindered the organisation's response to the approach: lack of knowledge and expertise, lack of a well-structured and linked strategy, unpreparedness to accommodate new BPCs, existence of a traditional and bureaucratic communication model, limited distribution of information, and ambiguous BPC governance. These findings demonstrated that the entity's decision-making process affected the success of BPC implementation.

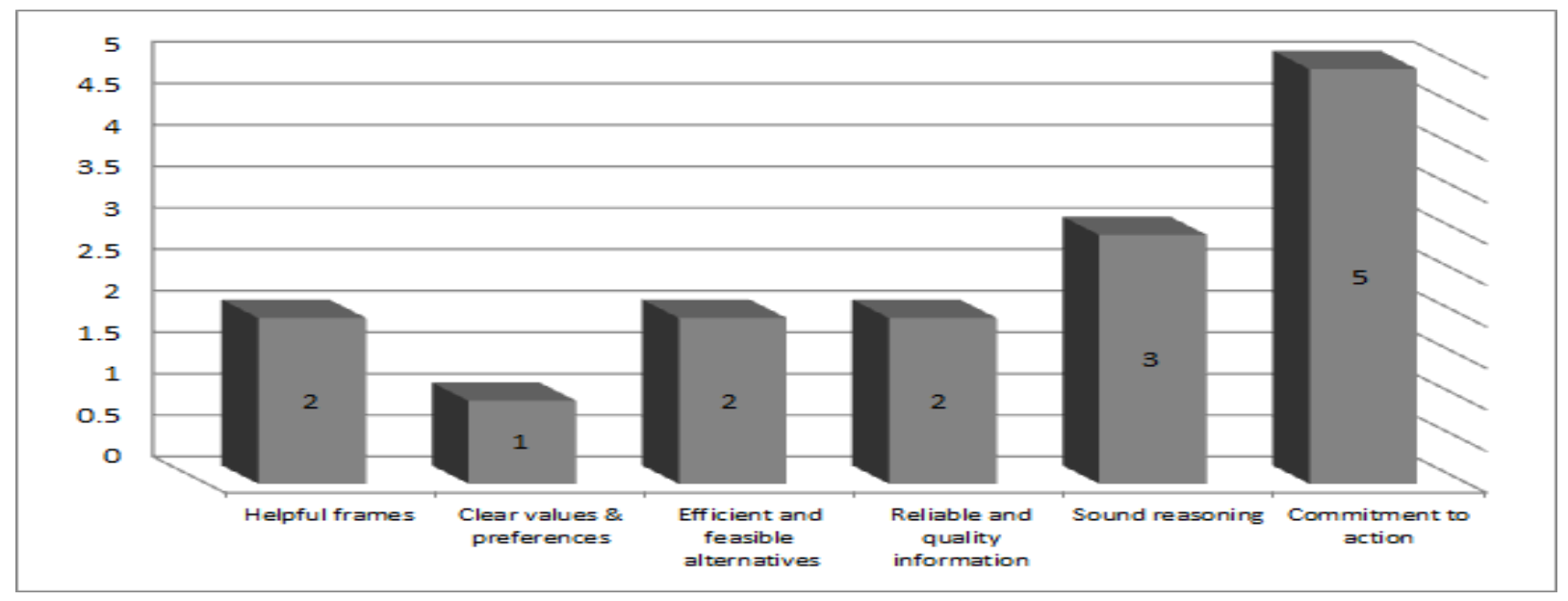

Figure 5: Decision quality rating

System dynamics patterns were used to identify the existence of feedback systems that induce ripple effects. From the follow-up interviews with stakeholders, it was verified that these kinds of patterns existed in their system and that they were due to the complex, causal loop relationships (Rosenberg et al., 2014).

\section{Results and Discussion}

From the analysed data in section 4, two main reasons for the problems encountered during the BPC projects were related to the BPC decision, that is, the formulation and execution of BPCDs within the Hafiz Program, and the complex, causal relationships within the business processes and their implementation. 
The first problem evidences an inefficient BPCD architecture within the Hafiz Program involving the hierarchical structure, governance and environment for quality decision formulation and execution. Through analysis of the operational data and surveys, it was established that the BPC decisions were ineffective. The second problem was the ripple effect that was triggered by the complex, causal relationships between the business processes and their implementations. System dynamics patterns models verified the output patterns, and the causal relationship of the technological implementation of the business process proved to be enormously complex.

From the analysed data, diverse types of trends - such as oscillations, over-collapse and negative and positive exponential behaviours - reflected the impacts of the BPC implementation and changes on the organisation's operation. Figure 3 shows several patterns that elucidated the most effective patterns of the BPC implementation. Figure 3 includes 12 behaviour patterns that summarise the 38 patterns identified in the operational and survey data. These types of behaviours in BPC indicated that there was no process improvement, which was due to suboptimal decisions that led to negative feedback loops and the generation of ripple effects. Consequently, the presence of a ripple effect, discovered through the analysed survey data, led us to proceed to resolve or minimise these ripple effects.

\subsection{HCMS Validation}

To validate the output from section 4, the results were firstly evaluated by the CM team in the focus group workshop, using the decision quality chain measurement (see Table 1). Table 1 presents the rating scores by the CM team (from 1 to 5 , where 1 is the lowest and 5 is the highest) before and after the implementation of HCMS framework. The researchers recorded the improvement percentage between the results of the first interview and the follow-up interview using the decision quality chain technique. Two BPC scenarios were then tested and validated using the proposed HCMS framework (see 5.3).

\begin{tabular}{lccccc}
\hline Decision quality attribute & Before HCMS & After HCMS & Improvement \% & \\
\cline { 1 - 3 } Helpful frames & 2 & 5 & $250 \%$ & \\
Clear values \& preferences & 1 & 4.5 & $450 \%$ & \\
Efficient and feasible alternatives & 2 & 5 & $250 \%$ & Table I. Validation \\
Reliable and quality information & 2 & 4.5 & $225 \%$ & of HCMS \\
Sramework \\
Cound reasoning & 3 & 5 & $166.6 \%$ & improvements in \\
Commitment to action & 5 & 5 & - & decision quality \\
\hline
\end{tabular}

As indicated in the decision quality analysis (Table 1), it is evident there was an improvement of $223 \%$ in the average scores and an increase of $450 \%$ in the weakest link of the decision quality. This indicates that there was substantial improvement in hierarchical decision making using the HCMS framework and this answers the research question: How can optimal BPC decisions in government organisations that are bound by tightly coupled temporal constraints be made more efficiently? Thus, automation of BPC decisions would enable rapid resolution of BPC problems, particularly as encountered by temporally constrained BPC. As a result, it is posited that automation of the BPC decision would resolve the problems encountered by temporally constrained BPC, i.e. TTC.

\subsection{HCMS Computation Method}

Figure 1 shows an example of the HCMS framework computation using the HEW methodology, which identifies the parameters of each layer from top to bottom. The computation structure consists of six layers: objectives, business processes, business process alternatives, applications, application alternatives and the causal analysis model (CAM). Figure 1 is a holistic view of all the parameters of the financial incentive objective. 
Figure 1 shows the best alternative BPC from the example of the HCMS computation framework. The HCMS computation process commenced by selecting the best alternatives to execute Hafiz Program objectives based on the constraints of low cost and minimum time. The computation began by selecting the best optimal alternative BPC options from a bottom-up approach. The steps for carrying out this calculation are summarised as follows:

1-Figure 1 shows the CAM for each alternative decision; CAM5 was selected as the lowest-cost alternative option $(139,000$ SAR $)$

2-The framework rose up and the linked application alternative was calculated, which was the Execute Callback Web (ECW) service, indicating the defined priority value of the ECW was (1), and multiplied it by the accumulated value $(139,000 \mathrm{SAR})$

3-The associated application was calculated, which was the modify bank account (MBA), calculated as 139,000 SAR

4-In the business process alternative layer, the framework calculated the modify account information (MAI) as the previous value (139,000 SAR); multiplied by the defined priority value for this process, which was weighted (3); that generated the output of $(417,000 \mathrm{SAR})$

5-In the business process layer, the framework achieved the value of the beneficiary payment processing (BPP) by multiplying the previous value $(417,000 \mathrm{SAR})$ by the value (2), which referred to the defined priority value of the BPP. The $(834,000$ SAR) value is the lowest cost that led to executing the financial incentive objective, which is the optimal BPC. The screenshot in Figure 6 recapitulates the best computed BPC alternatives from the HCMS computation example (Figure 1).

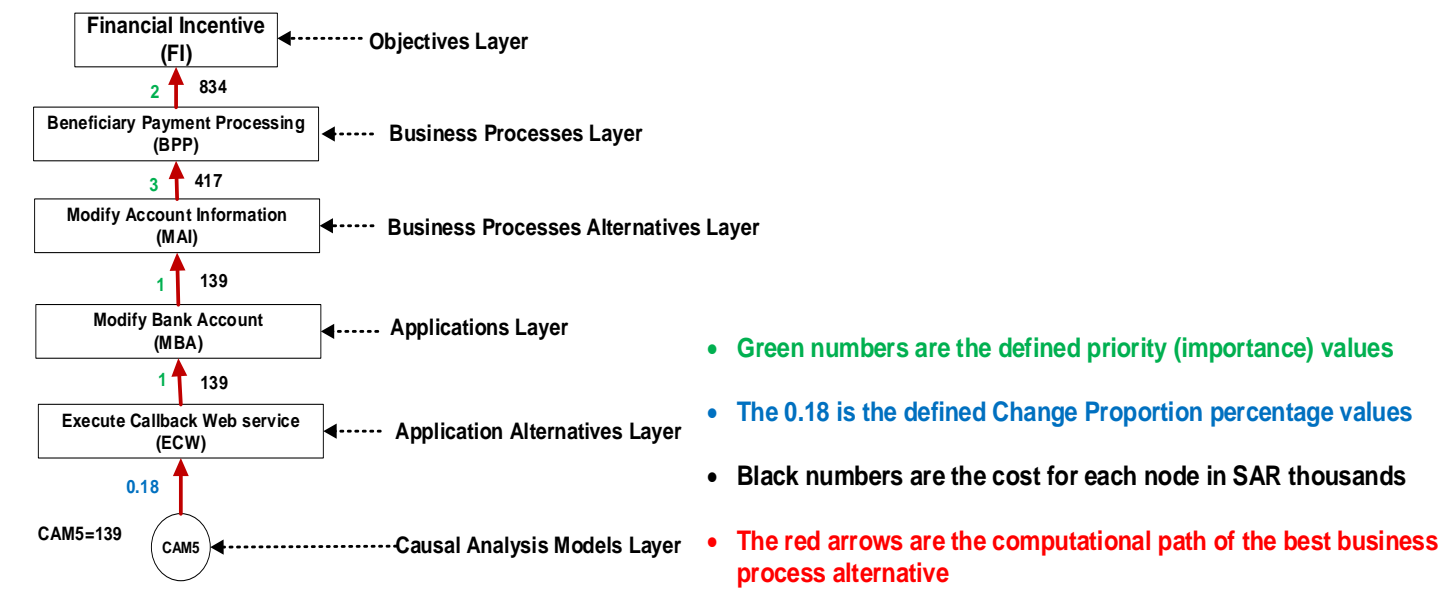

Figure 6. Summary of the best computed BPC alternatives from Figure 1

\subsection{Testing Two Scenarios}

To test the process of designing the HCMS framework and causal analysis models (CAMs), two new alternative scenarios were selected to define the causal relationship and examine the impact of the change in two ways, calculating the time and cost of processing. The Add New Beneficiary and the Cutting Budget business process alternatives are crucial to the Hafiz Program, thus using the HCMS framework to decide which the best BPC alternative approach to select based on the processing time and cost. The testing of the two scenarios required the creation of three tables to define the causal relationships, the estimated processing time to implement the business process change, and the estimated cost of the new implementation.

\subsubsection{Add New Beneficiary Alternative Scenario (BPCA1)}

The selected scenario is highly relevant to the organisation, which is investigating the potential of adding new beneficiaries who still do not have Saudi nationality but have either a Saudi father or mother. The scenario provides 
an excellent opportunity to compare the unexecuted business process alternative with another viable alternative. Thus, the change requires add, update and validate processes. Table 2 indicates the causal relationships (CRs) between the business processes, Table 3 presents calculations of the implementation cost and time for the proposed scenario, and Figure 7 depicts the causal relationships between the business processes. The change proportion for this scenario was 0.11 and is defined by the CM team based on the importance and priority of the occurrence of the business processes scenarios.

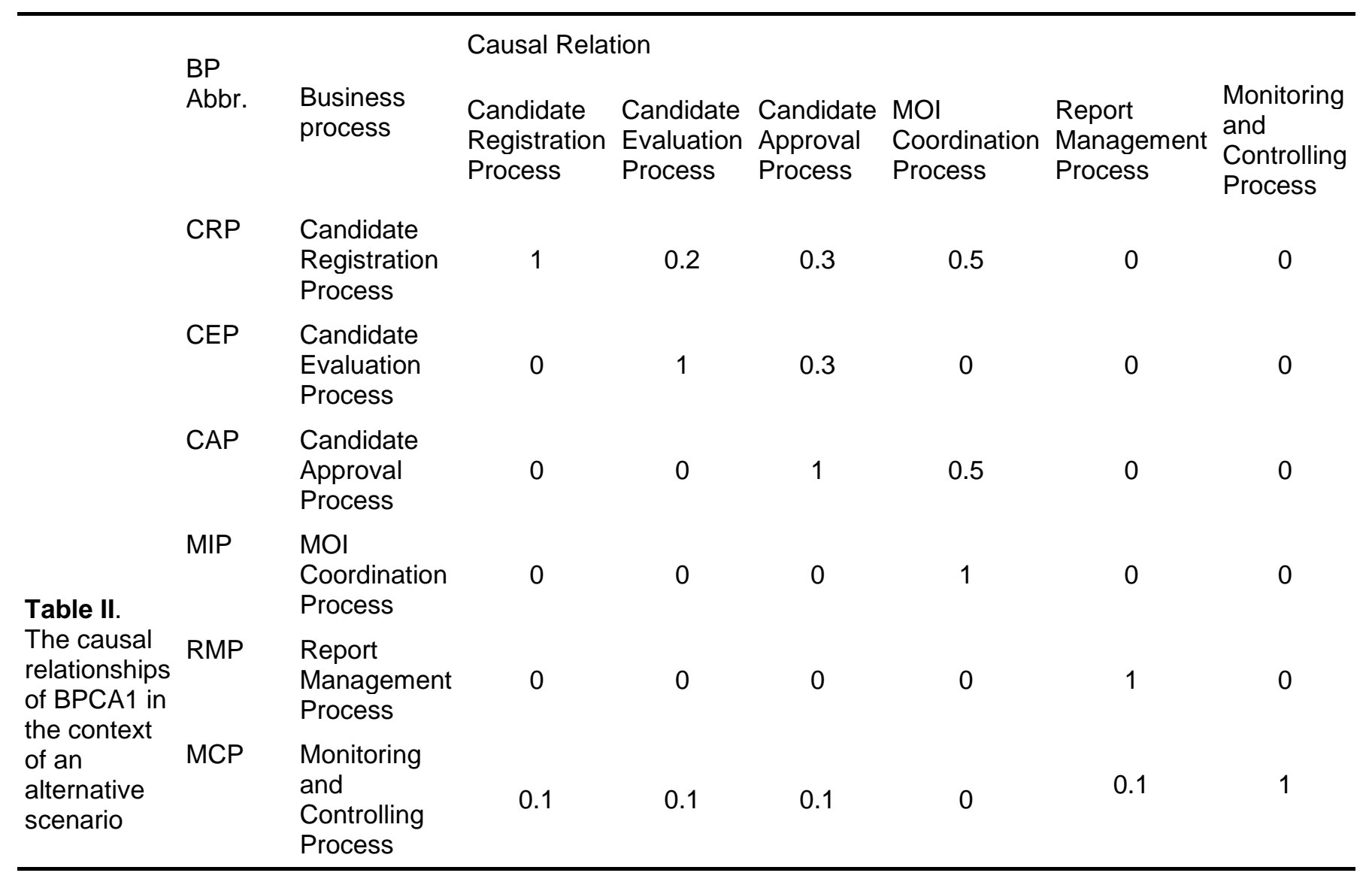

Table III.

Business

Process (BP) Implementation Cost and Time for BPCA1

\section{Business \\ Process}

Time

M/days

Cost in SAR $\quad 200,000.00 \quad 400,000.00$

$\begin{array}{ll}\text { Candidate } & \text { Candidate } \\ \text { Registration } & \text { Evaluation } \\ \text { Process } & \text { Process } \\ & \end{array}$

40

80
Candidate $\mathrm{MOI}$

Approval

Process

60

Coordination

Process

100

$300,000.00 \quad 500,000.00$

Report
Management
Process

10

$50,000.00$
Monitoring and Controlling Process

20

$100,000.00$ 


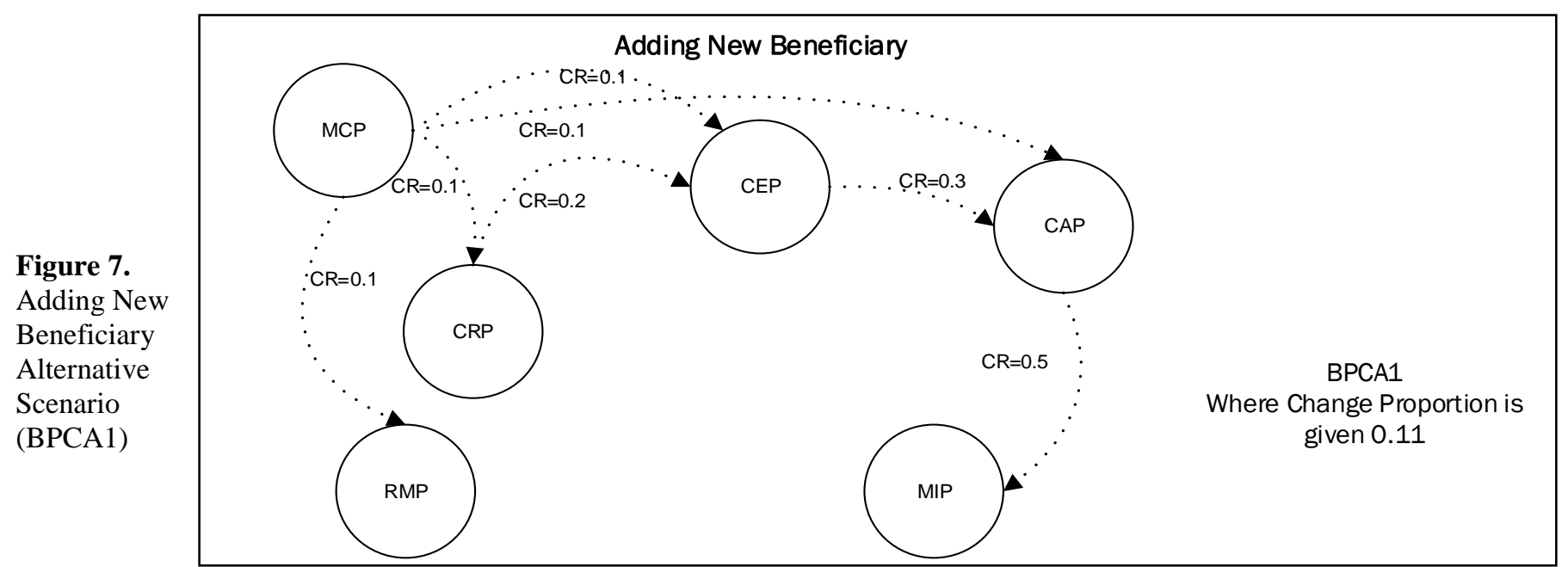

\subsubsection{Cutting Budget Alternative Scenario (BPCA2)}

This scenario can have two outcomes: decrease incentives or decrease the number of beneficiaries. Thus, the change requires add, update and validate processes. Table 4 indicates the causal relationships (CRs) between the business processes, Table 5 presents calculations of the implementation cost and time for the proposed scenario, and Figure 8 depicts the causal relationships between the business processes. The change proportion is defined by the CT for this scenario as 0.15 and is defined by the CM team and based on the importance and priority of the occurrence of the business processes scenarios.

BP

Abbr. Business

process

Causal Relation

$\begin{array}{lll}\text { Candidate } & \text { Candidate } & \text { Candidate } \\ \text { Registration } & \text { Evaluation Approval } \\ \text { Process } & \text { Process } & \text { Process }\end{array}$

$\begin{array}{lll}\text { Beneficiary } & \text { Report } & \text { Monitoring } \\ \text { Payment } & \text { Management } & \text { and } \\ \text { Processing } & \text { Pontrolling } \\ & \text { Process } & \text { Process }\end{array}$

\begin{tabular}{|c|c|c|c|c|c|c|c|c|}
\hline CRP & $\begin{array}{l}\text { Candidate } \\
\text { Registration } \\
\text { Process }\end{array}$ & 1 & 0.2 & 0.3 & 0.7 & 0 & 0 & \\
\hline CEP & $\begin{array}{l}\text { Candidate } \\
\text { Evaluation } \\
\text { Process }\end{array}$ & 0 & 1 & 0.3 & 0 & 0 & 0 & \\
\hline CAP & $\begin{array}{l}\text { Candidate } \\
\text { Approval } \\
\text { Process }\end{array}$ & 0 & 0 & 1 & 0.7 & 0 & 0 & \\
\hline BPP & $\begin{array}{l}\text { Beneficiary } \\
\text { Payment } \\
\text { Processing }\end{array}$ & 0 & 0 & 0 & 1 & 0 & 0 & \\
\hline RMP & $\begin{array}{l}\text { Report } \\
\text { Management } \\
\text { Process }\end{array}$ & 0 & 0 & 0 & 0 & 1 & 0 & $\begin{array}{l}\text { Table IV. } \\
\text { A demonstration } \\
\text { of the causal } \\
\text { relationships of }\end{array}$ \\
\hline MCP & $\begin{array}{l}\text { Monitoring } \\
\text { and } \\
\text { Controlling } \\
\text { Process }\end{array}$ & 0.1 & 0.1 & 0.1 & 0 & 0.1 & 1 & $\begin{array}{l}\text { BPCA2 in the } \\
\text { context of an } \\
\text { alternative } \\
\text { scenario }\end{array}$ \\
\hline
\end{tabular}

CRP Candidate

Registration

Candidate

Evaluation

Candidate

Approval

Process

Payment

Processing

Management

Monitoring

Controlling

Process 


\begin{tabular}{|c|c|c|c|c|c|c|c|}
\hline $\begin{array}{l}\text { Business } \\
\text { Process }\end{array}$ & $\begin{array}{l}\text { Candidate } \\
\text { Registration } \\
\text { Process }\end{array}$ & $\begin{array}{l}\text { Candidate } \\
\text { Evaluation } \\
\text { Process }\end{array}$ & $\begin{array}{l}\text { Candidate } \\
\text { Approval } \\
\text { Process }\end{array}$ & $\begin{array}{l}\text { Beneficiary } \\
\text { Payment } \\
\text { Processing }\end{array}$ & $\begin{array}{l}\text { Report } \\
\text { Management } \\
\text { Process }\end{array}$ & $\begin{array}{l}\text { Monitoring } \\
\text { and } \\
\text { Controlling } \\
\text { Process }\end{array}$ & \\
\hline $\begin{array}{l}\text { Time } \\
\text { M/days }\end{array}$ & 40 & 80 & 60 & 10 & 10 & 20 & \multirow{2}{*}{$\begin{array}{l}\text { Business Process } \\
\text { (BP) - } \\
\text { Implementation } \\
\text { Cost and Time for } \\
\text { BPCA2 }\end{array}$} \\
\hline Cost in SAR & $200,000.00$ & $400,000.00$ & $300,000.00$ & $50,000.00$ & $50,000.00$ & $100,000.00$ & \\
\hline
\end{tabular}

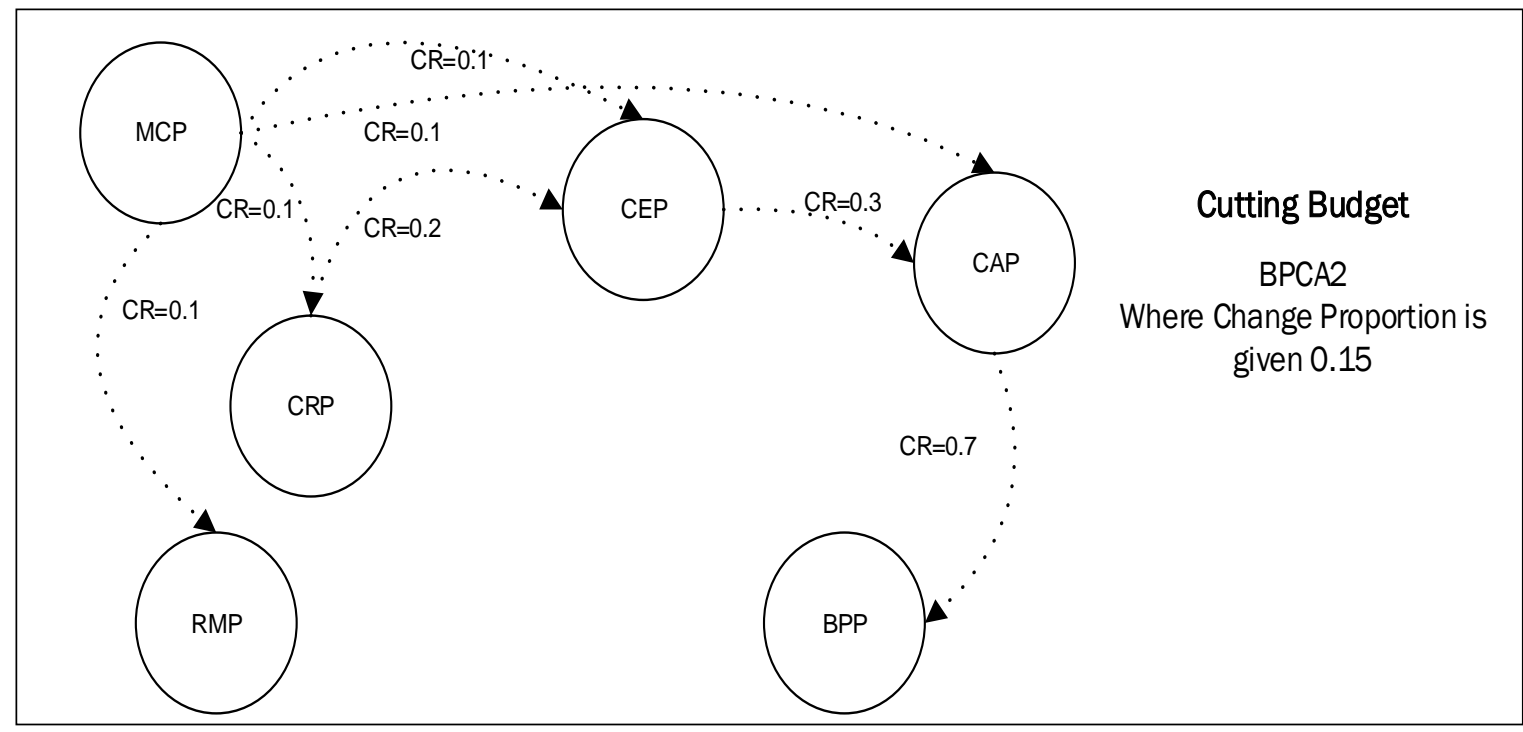

Figure 8.

Cutting Budget

Alternative

Scenario

(BPCA2)

The following table elicited the cost and time after the causal relationship was calculated for all the related business processes.

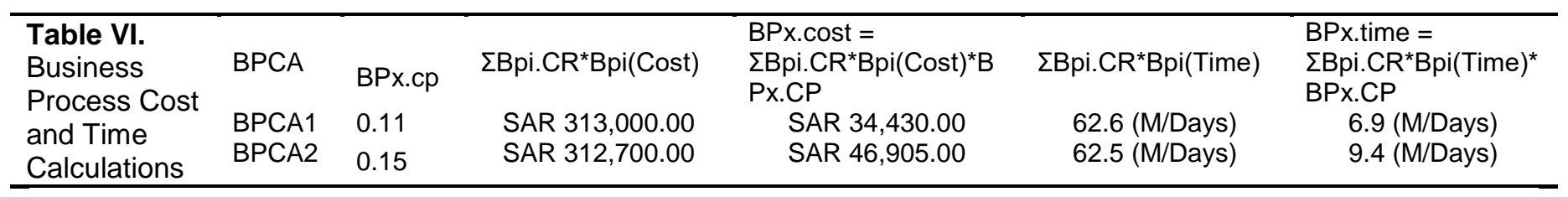

Table 6 indicates that the cost to execute the BPCA1 and BPCA2 is vastly reduced to SAR $34,430.00$ and SAR 46,905.00 respectively, and the execution time is notably decreased to 6.9 and 9.4 working-days respectively. As such, the HCMS framework technique proves that BPC decisions would be significantly improved. This finding allows us to proceed to automate the BPC decision framework using models adopted and tailored from decision sciences. The results of the tested two scenarios show that the best alternative BPC scenario could be defined, selected from alternative scenarios, and the right path identified using creative HCMS computation procedures.

\subsection{Practical Findings}

The results from the test two scenarios showed the feasibility of automating a BPCD framework. The process of calculation, if implemented through a computational model, would offer vast benefits such as to eliminate or reduce decision biases, enhance accountability and transparency, reduce cost and time (Wang et al., 2017), and minimise negative ripple effects from poor BPCDs. Further, the computational framework hierarchically structures business 
process relationships in a systematic way, and this would reduce ambiguity regarding who does what and when. Another advantage is the ability to evaluate alternatives that can promote knowledge and trust in the workplaces. The model is derived from decision trees and an analytical hierarchical process (Alrabiah \& Drew, 2018), and is tailored to address this problem area. It is suggested that this framework would allow organisations and practitioners to execute and implement BPCD efficiently and systematically. The manual calculation of the two scenarios implies that further benefit would be achieved by programming this framework in a software which would make it easier to judge and evaluate.

\section{Conclusion and Further Scope}

The research used the Hafiz Program in Saudi Arabia as a case study of the BPCDs imposed by exogenous organisations in the public sector. Extant literature provided a paucity of studies examining the timing of decisions in the implementation or change of business processes. Causes of failure in BPC implementation were examined in an organisation where a complex decision structure exists, information ambiguity, hierarchical structural problems, uncertainty in decision alternatives, decision model anomalies and other issues hindering the success of optimal BPCDs.

This research paper concentrated on the challenge of achieving optimal and efficient BPCD that require tight compliance with regulators' temporal constraints. The results of the study indicate reasons why this particular organisation might have failed to implement optimal BPCDs within tightly-coupled temporal constraints (TTCs). Seventy-six percent of the implemented business process changes encountered anomalies generated from unsound process change decisions. The high percentage of the anomalies confirmed the failing of BPCDs under TTCs.

Analysis showed inefficient BPCD architecture and ambiguity of decision formulation were the main factors hindering the success of BPC. These factors were responsible for $76 \%$ of BPCDs implementation failures that were amplified by the complexity of multiple relationships, and the ripple effects that stemmed from those relationships. To achieve an optimum decision-making process, a new computational framework named the hierarchical change management structure (HCMS) was constructed to analytically organise and create a rigorous BPCD framework that could resolve uncertainty and reduce any negative ripple effects. The HCMS framework successfully calculated the cost and time required to estimate the best change options and probable impacts. Furthermore, the HCMS generated a high rate of improvement, with a $230 \%$ score in change decision quality, and identified the weakest link in the organisation's provision of decision quality. This served to answer the research question: how can optimal BPC decisions in government organisations that are bound by tightly-coupled temporal constraints be made more efficiently?

Improper hierarchical decision structure and complex relationships in organisations were found to be the most crucial factors hindering the case of the organisation's ability to make well-structured change decisions. Workshops were arranged with the organisation to tackle these issues; the hierarchical change management structure framework was devised, and causal analysis modelling was used to assist in analysing its BPCD system.

The HCMS framework is a step and an invitation to improve and automate the BPCD. Government organisations and private firms would benefit from the HCMS framework in many ways. Firms could easily determine hierarchical decision structure problems and systematically solve BPCD. The study encourages scholars, technology firms and practitioners to use and improve upon this framework. The outcome of this research assists to formulise a systematic BPCD framework that is otherwise currently unavailable. Moreover, the practical use of the proposed framework has potential to impact the quality of organisational decision making.

This HCMS framework has been applied in a single case study for proof-of-concept of solving BPCDs, and due to the research design the findings are not generalisable on other BPCDs cases. Future research could extend its application to broader domains that have multi attribute structures and environments. The evaluation processes of the proposed HCMS framework are currently based on subjective metrics. Confirmation of the applicability of this framework can 
be enhanced by making links from chosen BPCDs to business process metrics, thereby providing concrete evidence of its effectiveness. Furthermore, forming an ontological representation of the HCMS framework in a crossorganisational approach would be an advantage of further validation of this framework. Developing software to handle and compute various causal relationships (CAMs) at all HCMS layers, including cross-organisational, would increase the applicability and usability of this framework. In addition, using the tailoring decision dialogue process (McNamee \& Celona, 2005) to implement process-driven HCMS execution would enable diverse stakeholders to interact with the HCMS during BPC decision execution.

\section{References}

Abernathy, W. J., \& Townsend, P. L. (1975). Technology, productivity and process change. Technological Forecasting and Social Change, 7(4), 379-396.

Adesola, S., \& Baines, T. (2005). Developing and evaluating a methodology for business process improvement. Business Process Management Journal, 11(1), 37-46.

Afflerbach, P., Bolsinger, M., \& Röglinger, M. (2016). An economic decision model for determining the appropriate level of business process standardization. Business Research, 9(2), 335-375.

Al-Harbi, K. (2012). Why will Hafiz aid end this year? Saudi Gazette. Retrieved from http://saudigazette.com.sa/article/2432/What-will-happen-to-Hafiz?

Al-Mashari, M., \& Zairi, M. (1999). BPR implementation process: an analysis of key success and failure factors. Business Process Management Journal, 5(1), 87-112.

Alotaibi, Y., \& Liu, F. (2017). Survey of business process management: challenges and solutions. Enterprise Information Systems, 11(8), 1119-1153.

Alrabiah, A., \& Drew, S. (2018). Deriving Organisational Business Process Change Factors using the Hierarchical Elicitation Workshop. International Journal of Business Process Integration and Management, 9(No. 1), 1-11. doi:10.1504/IJBPIM.2018.10013982

AlShihi, H. (2006). Critical Factors in the Adoption and Diffusion of E-government Initiatives in Oman. Victoria University,

Aluwaisheg, A. (2012). Employment incentives should not become a welfare program. Arab News. Retrieved from http://www.arabnews.com/\%5Btermalias-raw\%5D/employment-incentives-should-not-become-welfareprogram

Amiyo, M., Nabukenya, J., \& Sol, H. G. (2010). Decision Enhancement and Improving Business Process Agility. Paper presented at the 6th Annual International Conference on Computing and ICT Research (ICCIR 2010).

Amiyo, M. R. (2012). Decision enhancement and business process agility. (PhD Thesis), University of Groningen, Groningen, The Netherlands.

Andin Wu, J., \& L' abbe Wu, N. (1991). A strategic planning model: structuring and analysing via the analytic hierarchy process. Industrial Management \& Data Systems, 91(6), 5-9.

Andrade, E., van der Aa, H., Leopold, H., Alter, S., \& Reijers, H. (2016). Factors Leading to Business Process Noncompliance and its Positive and Negative Effects: Empirical Insights from a Case Study. Paper presented at the 22nd Americas Conference on Information Systems, AMCIS 2016, San Diego, CA, USA, August 11-14, 2016, San Diego, CA, United States.

Ariouat, H., Hanachi, C., Andonoff, E., \& Benaben, F. (2017). A Conceptual Framework for Social Business Process Management. Procedia Computer Science, 112, 703-712.

Azar, A. T. (2012). System dynamics as a useful technique for complex systems. International Journal of Industrial and Systems Engineering, 10(4), 377-410.

Bandara, W., Gable, G. G., \& Rosemann, M. (2005). Factors and measures of business process modelling: model building through a multiple case study. European Journal of Information Systems, 14(4), 347-360.

Barbacci, M. R., Ellison, R. J., Lattanze, A., Stafford, J., Weinstock, C. B., \& Wood, W. (2003). Quality Attribute Workshops (QAWs). Retrieved from Pittsburgh: http://resources.sei.cmu.edu/library/assetview.cfm?asset|D=6687

Barlas, Y. (2007). System dynamics: systemic feedback modeling for policy analysis. SYSTEM, 1, 59. 
Brenner, M., Coners, A., \& Matthies, B. (2015). Process capital as strategic success factor. In Handbook on Business Process Management 2 (pp. 133-152): Springer.

Bum, J., \& Robins, G. (2007). A Virtual Organisation Model for E-Government (Vol. 9).

Burlton, R. T. (2015). Delivering business strategy through process management. In Handbook on Business Process Management 2 (pp. 45-78): Springer.

Cadle, J., Paul, D., \& Turner, P. (2010). Business analysis techniques: 72 essential tools for success: BCS, The Chartered Institute.

Cameron, E., \& Green, M. (2015). Making sense of change management: A complete guide to the models, tools and techniques of organizational change: Kogan Page Publishers, 2015.

Cardoso, E., Almeida, J. P. A., Guizzardi, R. S., \& Guizzardi, G. (2013). A method for eliciting goals for business process models based on non-functional requirements catalogues. Frameworks for Developing Efficient Information Systems: Models, Theory, and Practice: Models, Theory, and Practice, 226.

Creswell, J. W. (2013). Research design: Qualitative, quantitative, and mixed methods approaches: Sage publications.

Davenport, T. H. (2013). Process innovation: reengineering work through information technology: Harvard Business Press.

Davenport, T. H., \& Short, J. E. (1990). The new industrial engineering: information technology and business process redesign.

Davenport, T. H., \& Stoddard, D. B. (1994). Reengineering: business change of mythic proportions? Mis Quarterly, 121-127.

Durcikova, A., \& Gray, P. (2009). How knowledge validation processes affect knowledge contribution. Journal of Management Information Systems, 25(4), 81-108.

Fan, B., \& Zhao, Y. (2017). The moderating effect of external pressure on the relationship between internal organizational factors and the quality of open government data. Government Information Quarterly, 34(3), 396-405.

Fisher, D. M. (2004). The business process maturity model. A practical approach for identifying opportunities for optimization. Business Process Trends, 9(4), 11-15.

Forrester, J. (1997). Road maps: A guide to learning system dynamics: MIT.

Fountain, J. E. (2001). Building the virtual state: Information technology and institutional change: Brookings Inst Press.

Goedertier, S., \& Vanthienen, J. (2006). Compliant and flexible business processes with business rules. Paper presented at the 7th Workshop on Business Process Modeling, Development and Support (BPMDS'06) at CAiSE'06.

Gong, Y., \& Janssen, M. (2012). From policy implementation to business process management: Principles for creating flexibility and agility. Government Information Quarterly, 29(suppl. 1), S61-S71.

Gong, Y., \& Janssen, M. (2017). The Impact of Social Business Process Management on Policy-making in eGovernment. Paper presented at the Proceedings of the 50th Hawaii International Conference on System Sciences.

Goodwin, P., \& Wright, G. (2014). Decision Analysis for Management Judgment (Vol. 4.). Chichester: Wiley Textbooks.

Grover, \& Kettinger, W. J. (1998). Business Process Change: Reengineering Concepts, Methods and Technologies. Hershey, Pa: IGI Global.

Grover, V. (1999). From business reengineering to business process change management: a longitudinal study of trends and practices. Engineering Management, IEEE Transactions on, 46(1), 36-46.

Grover, V., \& Kettinger, W. J. (2000). Process think: winning perspectives for business change in the information age: Idea Group Pub.

Grover, V., \& Otim, S. (2009). A Framework for Business Process Change Requirements Analysis. In Design Requirements Engineering: A Ten-Year Perspective (pp. 327-351): Springer, 2009.

Grunig, R., \& Kuhn, R. (2013). Successful decision-making: a systematic approach to complex problems (Vol. 82). New York;Berlin;: Springer.

Guha, S., Grover, V., Kettinger, W. J., \& Teng, J. T. C. (1997). Business process change and organizational performance: exploring an antecedent model. Journal of Management Information Systems, 119-154. 
Gwo-Hshiung, T., Tzeng, G. H., \& Huang, J.-J. (2011). Multiple attribute decision making: Methods and applications: Chapman \& Hall.

Hammer, M. (1990). Reengineering work: don't automate, obliterate. harvard business review, 68(4), 104-112.

Hammer, M., \& Champy, J. (2009). Reengineering the Corporation: Manifesto for Business Revolution, A: Zondervan.

Han, H.-S. (2003). Business process change design from decision model perspective. Management Science and Financial Engineering, 9(2), 21-46.

Harmon, P. (2003). Business process change: a manager's guide to improving, redesigning, and automating processes: Morgan Kaufmann.

Harmon, P. (2010). Business process change: A guide for business managers and BPM and Six Sigma professionals: Morgan Kaufmann.

Harmon, P. (2014). Business process change (Third ed.): Morgan Kaufmann, 2014.

Harmon, P. (2015). The scope and evolution of business process management. In J. v. Brocke \& M. Rosemann (Eds.), Handbook on business process management 1 ( 2 ed., pp. 37-80). Berlin/Heidelberg, Germany: Springer Verlag.

Herzog, N., Usatin, R., \& Fizazi-Hawkins, M. (2014). Ripple Effects of Process Change. The Foundation Review, 6(3), 22. doi:10.9707/1944-5660.1209

Hoque, Z., Barnabè, F., \& Busco, C. (2012). The causal relationships between performance drivers and outcomes: Reinforcing balanced scorecards' implementation through system dynamics models. Journal of Accounting \& Organizational Change, 8(4), 528-538.

Houy, C., Fettke, P., \& Loos, P. (2015). Business process frameworks. In Handbook on Business Process Management 2 (pp. 153-175): Springer.

Huizing, A., Koster, E., \& Bouman, W. (1997). Balance in business reengineering: an empirical study of fit and performance. Journal of Management Information Systems, 14(1), 93-118.

Jaklič, J., \& Štemberger, M. I. (2005). A methodology for a business process change in public sector. Systems Integration, 38.

Javidroozi, V., Amini, A., Cole, A., \& Shah, H. (2014). Business Process Change in Enterprise Systems Integration: Challenges and Opportunities. Paper presented at the 16th International Conference on Enterprise Information Systems (ICEIS 2014).

Javidroozi, V., Shah, H., Amini, A., \& Feldman, G. (2016). Business process change: A guide for implementers. Paper presented at the Proceedings of the International Conference on e-Learning, e-Business, Enterprise Information Systems, and e-Government (EEE).

Jurisch, M. (2014). IT-enabled Business Process Change in Private and in Public Sector Organizations. München, Technische Universität München, Diss., 2014,

Jurisch, M., Cuno, J., Palka, W., Wolf, P., \& Krcmar, H. (2012). An integrative model of IT-enabled business process change: causal structures in theory, research and practice. Paper presented at the System Science (HICSS), 2012 45th Hawaii International Conference on.

Jurisch, M., Ikas, C., Wolf, P., \& Krcmar, H. (2013). Key Differences of Private and Public Sector Business Process Change. e-Service Journal, 9(1), 3-27.

Jurisch, M., Palka, W., Wolf, P., \& Krcmar, H. (2014). Which capabilities matter for successful business process change? Business Process Management Journal, 20(1), 47-67.

Jurisch, M., Rosenberg, Z., \& Krcmar, H. (2016). Emergent risks in business process change projects. Business Process Management Journal, 22(4), 791-811.

Kavakli, V., \& Loucopoulos, P. (1999). Goal-driven business process analysis application in electricity deregulation. Information Systems, 24(3), 187-207.

Kherbouche, O. M., Ahmad, A., Bouneffa, M., \& Basson, H. (2013). Analyzing the ripple effects of change in business process models. Paper presented at the Multi Topic Conference (INMIC), 2013 16th International.

Kolbin, V. V. (2003). Decision Making and Programming: World Scientific.

Krueger, R. A., \& Casey, M. A. (2014). Focus groups: A practical guide for applied research: Sage publications.

Langer, A. M. (2017). Information Technology and Organizational Learning: Managing Behavioral Change in the Digital Age (3rd ed.). Milton: CRC Press, 2017. 
Lau, E. (2003). Challenges for e-government development. Paper presented at the 5th Global Forum on Reinventing Government.

Law, K. H., Lau, G., Kerrigan, S., \& Ekstrom, J. A. (2014). REGNET: Regulatory information management, compliance and analysis. Government Information Quarterly, 31, S37-S48.

Lee, M. L. (1998). Change impact analysis of object-oriented software: George Mason University Virginia.

Lin, F., \& Shayo, C. (2012). Systems Dynamics Modeling for Collaboration and Information Sharing on Supply Chain Performance and Value Creation. Journal of International Technology and Information Management, 21(4), 67.

Lönn, C.-M., \& Uppström, E. (2013). Process management challenges in swedish public sector: a bottom up initiative. Paper presented at the International Conference on Electronic Government.

Luftman, J. N., Lewis, P. R., \& Oldach, S. H. (1993). Transforming the enterprise: The alignment of business and information technology strategies. IBM Systems Journal, 32(1), 198-221.

Luna-Reyes, L. F., \& Andersen, D. L. (2003). Collecting and analyzing qualitative data for system dynamics: methods and models. System Dynamics Review, 19(4), 271-296.

Luo, W., \& Alex Tung, Y. (1999). A framework for selecting business process modeling methods. Industrial Management \& Data Systems, 99(7), 312-319.

Matheson, J. (2005). Decision analysis= decision engineering. In J. C. Smith \& H. J. Greenberg (Eds.), 2005 Tutorials in Operations Research: Emerging Theory, Methods, and Applications (pp. 195-212): INFORMS, 2005.

McKenzie, J., van Winkelen, C., \& Grewal, S. (2011). Developing organisational decision-making capability: a knowledge manager's guide. Journal of Knowledge Management, 15(3), 403-421. doi:10.1108/13673271111137402

McNamee, P., \& Celona, J. (2005). Decision analysis for the professional: SmartOrg, Incorporated.

Melão, N., \& Pidd, M. (2000). A conceptual framework for understanding business processes and business process modelling. Information systems journal, 10(2), 105-129.

Neumann, J. (2014). A framework for monitoring and evaluating critical success factors in strategic change programme implementation: a case study of a global industrial company in the energy sector. Northumbria University,

Pateli, A., \& Philippidou, S. (2011). Applying Business Process Change (BPC) to Implement Multi-agency Collaboration: The Case of the Greek Public Administration.

Paul, D., Yeates, D., \& Cadle, J. (2014). Business analysis (3rd ed.): BCS, The Chartered Institute for IT, 2014.

Ploesser, K., Recker, J. C., \& Rosemann, M. (2008). Towards a classification and lifecycle of business process change.

Quinlan, J. R. (1986). Induction of decision trees. Machine learning, 1(1), 81-106.

Raghu, T., \& Vinze, A. (2007). A business process context for Knowledge Management. Decision Support Systems, 43(3), 1062-1079.

Rao, L., Mansingh, G., \& Osei-Bryson, K.-M. (2012). Building ontology based knowledge maps to assist business process re-engineering. Decision Support Systems, 52(3), 577-589.

Rinderle, S., Reichert, M., \& Dadam, P. (2004). Correctness criteria for dynamic changes in workflow systems-a survey. Data \& Knowledge Engineering, 50(1), 9-34.

Rosenberg, Z., Jurisch, M., Schermann, M., \& Krcmar, H. (2014). Using Case Survey Methodology to Extract Variables and Causal Links: An Example from Studying Business Process Change. Paper presented at the Proceedings of the 32nd International Conference of the System Dynamics Society, Wiley, Delft, Netherlands.

Saaty, T. L. (1977). A scaling method for priorities in hierarchical structures. Journal of mathematical psychology, 15(3), 234-281.

Saaty, T. L. (1990a). Decision making for leaders: the analytic hierarchy process for decisions in a complex world: RWS publications.

Saaty, T. L. (1990b). How to make a decision: the analytic hierarchy process. European Journal of Operational Research, 48(1), 9-26.

Saaty, T. L. (2008). Decision making with the analytic hierarchy process. International journal of services sciences, 1(1), 83-98.

Scholl, H. (2004). Current practices in e-government-induced business process change (BPC). Paper presented at the Proceedings of the 2004 annual national conference on Digital government research. 
Segatto, M., Inês Dallavalle de Pádua, S., \& Pinheiro Martinelli, D. (2013). Business process management: a systemic approach? Business Process Management Journal, 19(4), 698-714.

Seligman, L., Lehner, P., Smith, K., Elsaesser, C., \& Mattox, D. (2000). Decision-centric information monitoring. Journal of Intelligent Information Systems, 14(1), 29-50.

Sikdar, A., \& Payyazhi, J. (2014). A process model of managing organizational change during business process redesign. Business Process Management Journal, 20(6), 971-998.

Simon, H. A. (1979). Rational decision making in business organizations. The American economic review, 493-513.

Škrinjar, R., \& Trkman, P. (2013). Increasing process orientation with business process management: Critical practices. International Journal of Information Management, 33(1), 48-60. doi:10.1016/j.ijinfomgt.2012.05.011

Smart, P. A., Maddern, H., \& Maull, R. S. (2009). Understanding business process management: implications for theory and practice. British Journal of Management, 20(4), 491-507.

Snowden, D. J., \& Boone, M. E. (2007). A leader's framework for decision making. harvard business review, 85(11), 68.

Soffer, P. (2005). Scope analysis: identifying the impact of changes in business process models. Software Process: Improvement and Practice, 10(4), 393-402.

Stemberger, M., \& Jaklic, J. (2007). Towards E-government by business process change-A methodology for public sector. International Journal of Information Management, 27(4), 221-232.

Sterman, J. (2000). Business Dynamics: Systems Thinking and Modeling for a Complex World with CD-ROM: McGrawHill Education.

Stufflebeam, D. (2001). Evaluation models. New directions for evaluation, 2001(89), 7-98.

Subramanian, N., \& Ramanathan, R. (2012). A review of applications of Analytic Hierarchy Process in operations management. International Journal of Production Economics, 138(2), 215-241.

Thomas, A. (2008). Business Process Change. published in Student Accountant.

Triantaphyllou, E., \& Mann, S. H. (1995). Using the analytic hierarchy process for decision making in engineering applications: some challenges. International Journal of Industrial Engineering: Applications and Practice, 2(1), 35-44.

Trkman, P. (2010). The critical success factors of business process management. International Journal of Information Management, 30(2), 125-134.

Vanhoenacker, J., Bryant, A., \& Dedene, G. (1999). Creating a knowledge management architecture for business process change. Paper presented at the Proceedings of the 1999 ACM SIGCPR conference on Computer personnel research.

Wang, C., Medaglia, R., \& Zheng, L. (2017). Towards a typology of adaptive governance in the digital government context: The role of decision-making and accountability. Government Information Quarterly.

Weske, M. (2012). Business process management: concepts, languages, architectures: Springer Science \& Business Media.

Wu. (2002). A model for implementing BPR based on strategic perspectives: an empirical study. Information \& management, 39(4), 313-324.

Yau, S. S., Collofello, J. S., \& MacGregor, T. (1978). Ripple effect analysis of software maintenance. Paper presented at the Computer Software and Applications Conference, 1978. COMPSAC'78. The IEEE Computer Society's Second International.

Zairi, M. (1997). Business process management: a boundaryless approach to modern competitiveness. Business Process Management Journal, 3(1), 64-80.

Zuiderwijk, A., \& Janssen, M. (2014). Open data policies, their implementation and impact: A framework for comparison. Government Information Quarterly, 31(1), 17-29. 
Appendix 1.

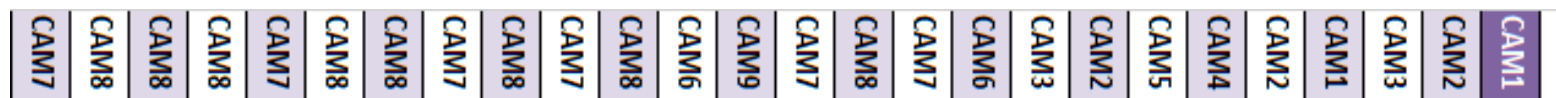

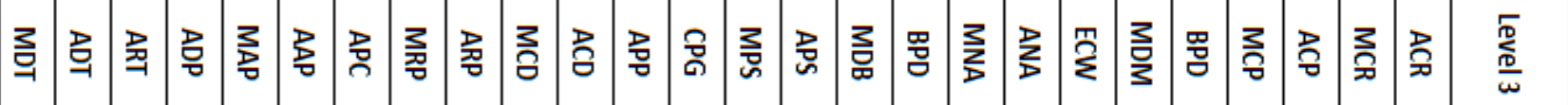

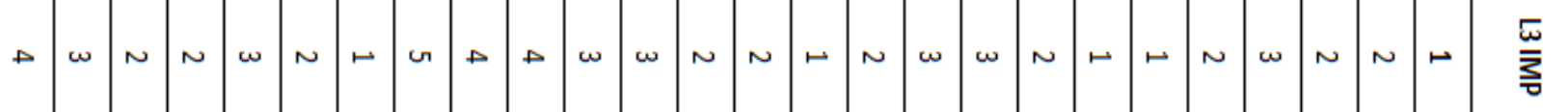

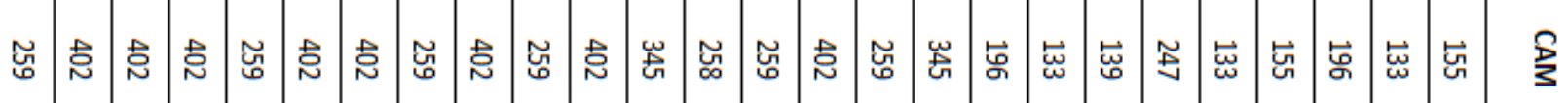

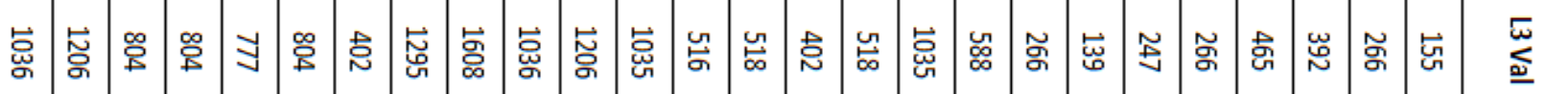

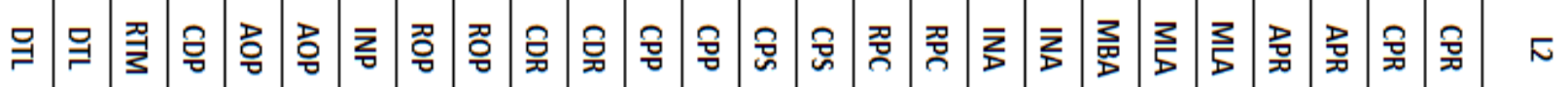

\begin{tabular}{|c|c|c|c|c|c|c|c|c|c|c|c|c|c|c|c|}
\hline$A$ & $N$ & $\omega$ & $N$ & $\vdash$ & $N$ & $\omega$ & $N$ & $\omega$ & $\vdash$ & $N$ & $\vdash$ & $\omega$ & $\omega$ & $N$ & $\frac{\pi}{3}$ \\
\hline 芯 & 皇 & 号 & $\exists$ & 总 & 忍 & 总 & 吢 & 莡 & 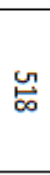 & ్̆ & 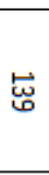 & $\tilde{E}$ & 岕 & 岕 & 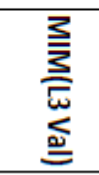 \\
\hline 莹 & 容 & 莽 & 忎 & 总 & 岧 & 岕 & 怘 & 荅 & $\stackrel{\text { 心 }}{\infty}$ & $\underset{\mathrm{N}}{\mathrm{N}}$ & 㤐 & 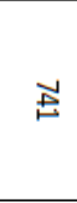 & 占 & $\stackrel{\omega}{\sigma}$ & 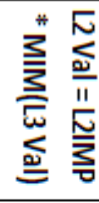 \\
\hline 忍 & 召 & 쫌 & $\sum_{0}$ & ż & $\sum_{0}$ & 쪾 & 咅 & 艿 & 妾 & $\frac{S}{2}$ & $\underline{\underline{Z}}$ & $\underline{\underline{Z}}$ & $\underline{z}$ & $\frac{3}{7}$ & E \\
\hline$\mapsto$ & & $\omega$ & & $N$ & & $N$ & & $\vdash$ & & $\vdash$ & & $\omega$ & & & 章 \\
\hline 宫 & & 莣 & & 总 & & $\stackrel{\omega}{\stackrel{\omega}{\circ}}$ & & $\stackrel{\text { 心̆ }}{\infty}$ & & $\underset{\mathrm{N}}{\mathrm{N}}$ & & 岕 & & & 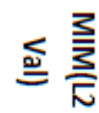 \\
\hline 宫 & & స్心 & & 号 & & 怘 & & $\stackrel{\text { 心 }}{\infty}$ & & $\underset{\mathrm{N}}{\mathrm{N}}$ & & 茪 & & & 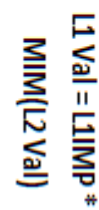 \\
\hline
\end{tabular}

Figure A1. HCMS Calculation Sheet 


\section{Appendix 2. Procedure to calculate the path value of the HCMS}

$$
\begin{array}{ll}
1 & \text { Calculate All CAM values } \\
2 & \text { Set } \mathrm{i}=\text { lowest level } \\
3 & \text { While } \mathrm{i}<>\text { Root } \\
4 & \text { For each node in level (i) } \\
5 & \text { Compute value using: } \\
\bigcap_{j=1}^{m} \text { Value }_{j} * R_{j} \\
6 & \\
7 & \text { Next Node } \\
8 & \mathrm{i}=\mathrm{i}+1 \\
& \text { End while }
\end{array}
$$

$\cap$ : This function returns the minimum value in a given set.

For example: $\cap(7,8,9,2,4,3)=2$ 


\section{Appendix 3 .}

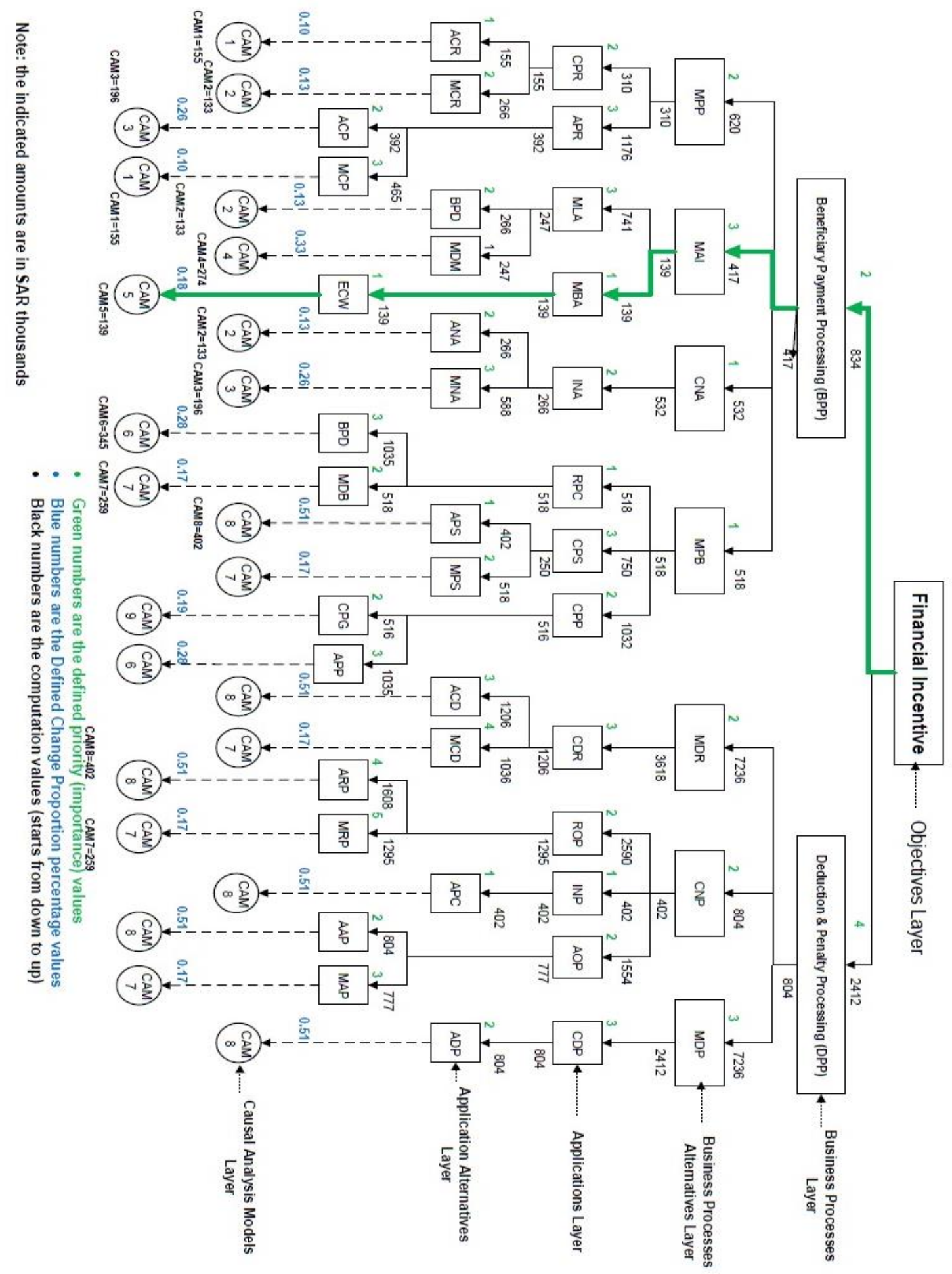

Figure A2-1. Examples of HCMS Computation (continued) 


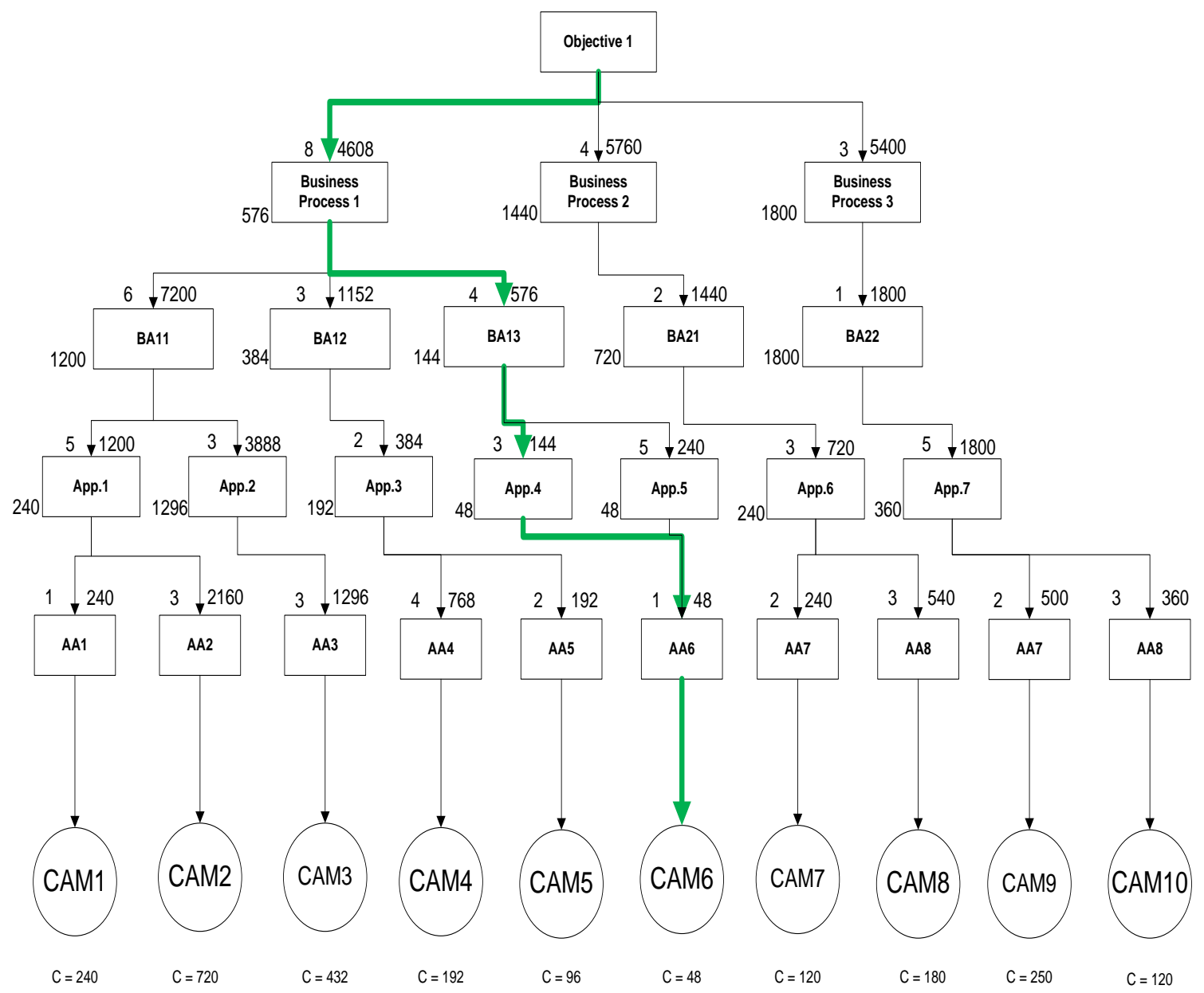

Figure A2-2. 


\section{Appendix 4. Algorithm for computing the Optimal BPC Decision using HCMS}

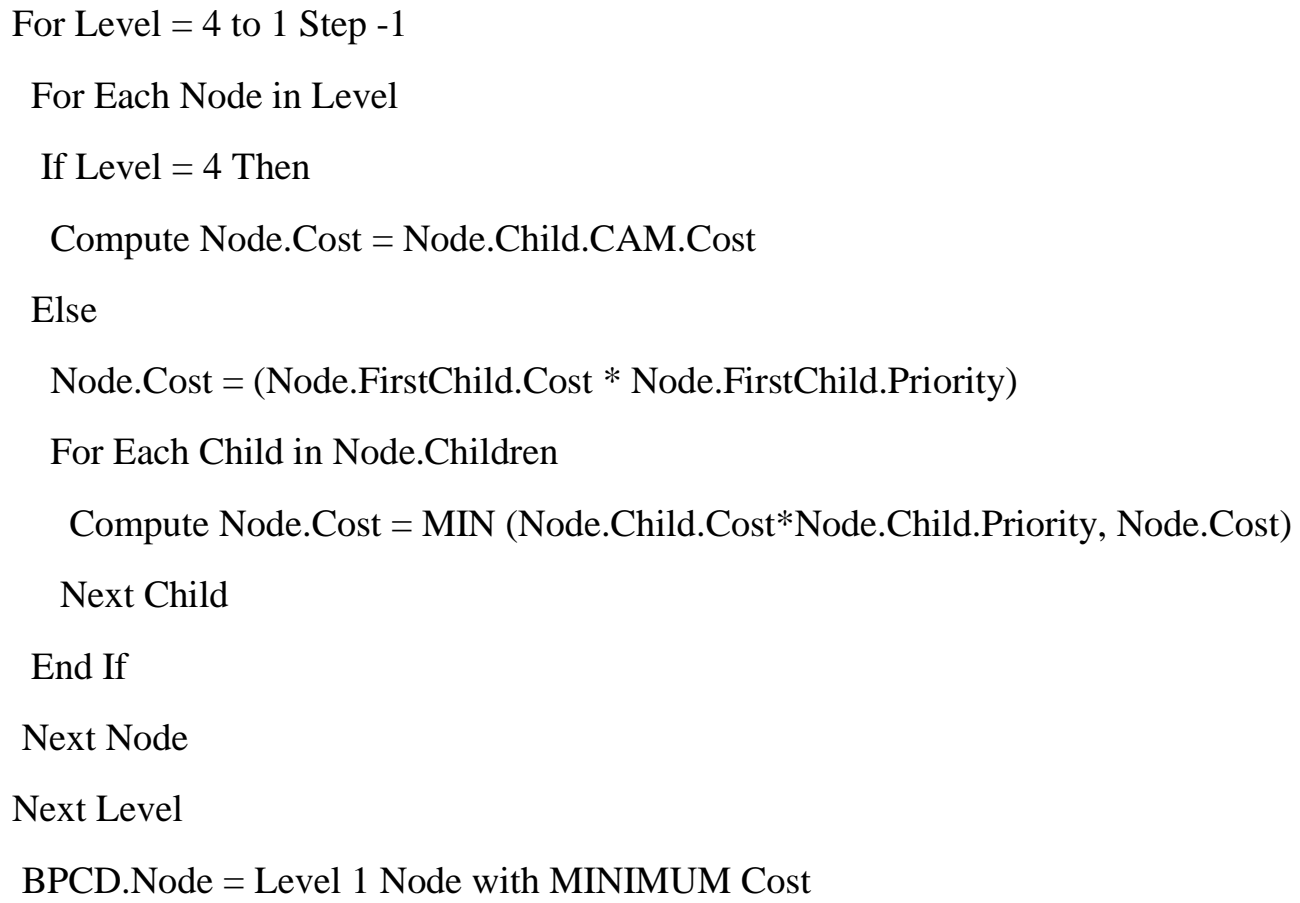

Where:

Node.Child: Is the direct Child of the Current Node

Node.Child.Cost: Prioritized Cost for the Node

Node.Child.Priority: This is Priority number assigned by the parent of the Node. In HCMS this is the value assigned to the Link between the Node, and its parent node.

Node.Children: are the Set of Children for the Node Node.FirstChild: This is the first Child of the Node

BPCD: Stands for Business Process Change Decision Variable

BPCD.Node: This is Level 1 Node with Minimal Cost. 


\section{Appendix 5. Glossary/Acronyms}

\begin{tabular}{lll}
\hline Terminology & Description \\
\cline { 2 - 3 } & BPC & Business Process Change \\
BPCD & Business Process Change Decision \\
BPM & Business Process Management \\
CAM & Causal Analysis Model \\
CLD & Causal Loop Diagram \\
CM Team & Change Management Team of the Hafiz Program, case study \\
DDP & Dialog Decision Process \\
EXP- & Exponential decline \\
EXP+ & Exponential growth \\
TTC & Tight Temporal Constraints \\
HCMS & Hierarchical Change Management Structure \\
HEW & Hierarchical Elicitation Workshop \\
IMP & Improvement \\
OCOL & Overshooting and Collapse \\
OPI & Operational Performance Indicator \\
OPM & Organization Performance Measurement \\
OSC & Oscillations \\
SEI & Software Engineering Institute \\
Stas & Stasis \\
\hline
\end{tabular}




\begin{tabular}{|c|c|c|}
\hline Terminology & Description & \\
\hline BPMO & Business Process Management Officer & \\
\hline BPP & Beneficiary Payment Processing & \\
\hline BTP & Beneficiary Training Process & \\
\hline CAP & Candidate Approval Process & \\
\hline CAPS & Candidate Application Processing System & \\
\hline CBO & Chief Business Officer & \\
\hline CEA & Chief Enterprise Architect & \\
\hline CEP & Candidate Evaluation Process & \\
\hline CIP & Coordination \& Integration Platform & \\
\hline CMP & Complaints Management Process & \\
\hline $\mathrm{COO}$ & Chief Operation Officer & \\
\hline CRP & Candidate Registration Process & \\
\hline CTO & Chief Technology Officer & \\
\hline DPP & Deduction \& Penalty Processing & \\
\hline DRP & Dispute Resolution Process & \\
\hline ESIR & Enhance Students Ineligibility Reason & \\
\hline FI & Financial Incentives (to encourage job seeking) & \\
\hline GOSIP & GOSI Coordination Process & \\
\hline HJSE & Help Job Seekers to find Employment & \\
\hline HMP & Hafiz Main Portal & \\
\hline HPM & Hafiz Program Manager & \\
\hline JMP & Job Matching Processing & \\
\hline MCIP & MCI Coordination Process & \\
\hline MCP & Monitoring and Controlling Process & \\
\hline MCS & Monitoring \& Control System & \\
\hline MFP & MOF Coordination Process & \\
\hline MHEP & MOHE Coordination Process & \\
\hline MIP & MOI Coordination Process & \\
\hline MLP & MOL Coordination Process & \\
\hline OCP & Organization Coordination Process & \\
\hline PPS & Payment Processing System & \\
\hline QAO & Quality Assurance Officer & \\
\hline RDP & Report \& Data Analysis Platform & \\
\hline RMP & Report Management Process & \\
\hline RUP & Resolve Unemployment Problem & \\
\hline SBA & Senior Business Architecture & \\
\hline SOM & Senior Operation Manager & Table II. Case Study Workshop \\
\hline STM & Senior Technology Manager & Terminology \\
\hline TBMD & Provide Training to Bridge Market Demand & \\
\hline TMS & Training Management System & \\
\hline
\end{tabular}




\begin{tabular}{|c|c|}
\hline Terminology & Description \\
\hline$\overline{\mathrm{AAP}}$ & Auto Append Policy \\
\hline $\mathrm{ACD}$ & Auto Change Deduction \\
\hline $\mathrm{ACP}$ & Auto Change Policy \\
\hline ACR & Auto Change Repository \\
\hline $\mathrm{ADP}$ & Auto Deduction Process \\
\hline $\mathrm{ADT}$ & Auto Delete Transaction \\
\hline ANA & Auto New Account \\
\hline AOP & Append Old Policy \\
\hline APC & Auto Policy Creation \\
\hline APP & Amend Payment Protocol \\
\hline APR & Amend Policy Rules \\
\hline APS & Auto Payment Sub-module \\
\hline ARP & Auto Replace Policy \\
\hline ART & Auto Rollback Transaction \\
\hline BPD & Business Process Driven \\
\hline CDP & Change Deduction Process \\
\hline CDR & Change Deduction Rules \\
\hline CNA & Create New Account \\
\hline CNP & Create New Policies \\
\hline CPG & Change Payment Gateway \\
\hline CPP & Change Payment Protocol \\
\hline $\mathrm{CPR}$ & Change Policy Repository \\
\hline CPS & Change Payment Sub-module \\
\hline DTL & Delete Transaction Log \\
\hline $\mathrm{ECW}$ & Execute Callback Web service \\
\hline INA & Insert New Account \\
\hline INP & Insert New Policy \\
\hline MAI & Modify Account Information \\
\hline MAP & Manual Append Policy \\
\hline MBA & Modify Bank Account \\
\hline MCD & Manual Change Deduction \\
\hline $\mathrm{MCP}$ & Manual Change Policy \\
\hline MCR & Manual Change Repository \\
\hline MDM & Manual DB Modification \\
\hline MDP & Modify Deduction Process \\
\hline MDR & Modify Deduction Rules \\
\hline MDT & Manual Delete Transaction \\
\hline MLA & Modify Local Account \\
\hline MNA & Manual New Account \\
\hline MPB & Modify Payment Business Process \\
\hline MPP & Modify Payment Policy \\
\hline MPS & Manual Payment Sub-module \\
\hline MRP & Manual Replace Policy \\
\hline RDP & Rollback Detection and Penalties \\
\hline ROP & Replace Old Policy \\
\hline RPC & Radical Payment Change \\
\hline RTM & Rollback Transaction Manager \\
\hline
\end{tabular}

Corresponding author: Abdulrahman Alrabiah can be contacted at: abdul.alrabiah@griffithuni.edu.au 